\title{
Schooling, occupation and cognitive function: evidence from compulsory schooling laws*
}

\author{
Emma Gorman ${ }^{\dagger}$
}

November 3, 2017

\begin{abstract}
This paper assesses whether additional schooling has lasting causal effects on cognitive function, and explores the role of occupation type in shaping these effects. Exploiting quasi-experimental variation from the 1972 raising of the school leaving age in England and Wales, an additional year of schooling improves working memory by one- to two-thirds of a standard deviation. Limited evidence was detected for causal effects on verbal fluency and numeric ability. Analyses of the underlying mechanisms show occupation can explain up to about one-fifth of schooling's effects on memory. However these figures are imprecisely estimated, and the role of occupation remains an area for further study.
\end{abstract}

Keywords: cognitive skills; ageing; education; causal mechanisms JEL codes: C14, I26, I28, J14, J24

*I am especially grateful to Ian Walker and Eugenio Zucchelli for many discussions and comments on this work. Thanks also to James Banks, Fabrizio Mazzonna and Giovanni Mellace for helpful feedback, and to Andy Dickerson for sharing, and providing assistance with, the O*NET data. This work was supported by funding from the Economic and Social Research Council. Earlier versions of this paper was circulated as "Does schooling have lasting effects on cognitive function? Evidence from compulsory schooling laws".

${ }^{\dagger}$ Department of Economics, Lancaster University Management School, LA1 4XY, Lancaster, United Kingdom. E-mail: e.gorman1@lancaster.ac.uk 


\section{Introduction}

Cognitive performance shapes economic, social and health outcomes over the lifecycle (Heckman et al., 2006; Wraw et al., 2015). While the efficacy of early intervention in improving cognitive performance is well studied, less is known about whether these outcomes are malleable outside of early childhood (Heckman, 2006). This study assesses whether secondary schooling has lasting causal effects on cognitive function-measured four decades after leaving school—and explores the role of occupation type in shaping these effects.

In later life, cognitive performance becomes an important component of healthy ageing and continued independent functioning (Beard et al., 2015). Among healthy individualsfree of clinical cognitive impairment-age-related reductions in cognitive performance can impede the ability to carry out daily activities (Tucker-Drob, 2011; Boyle et al., 2012) and manage financial planning decisions (Hsu and Willis, 2013). This has important implications for continued labor market engagement and retirement planning, as state pension ages rise and supporting continued labour market participation is a central policy focus (OECD, 2006; Department for Work and Pensions, 2013).

Declining cognitive performance is also a risk factor for morbidity and mortality. One example is dementia, for which declines in cognitive function, especially memory, are a precursor. Estimates from 2016 showed that 800,000 people suffered from dementia in the United Kingdom, with a total cost of 26 billion pounds per year-largely comprising informal care costs (Prince et al., 2014). Even after accounting for the observed and projected reductions in age-specific incidence rates, the prevalence of dementia is forecast to increase to 1.2 million by 2040, representing a vast increase in both human and economic costs (Ahmadi-Abhari et al., 2017).

Yet cognitive impairment is not an inevitable consequences of ageing, and a large body of work has sought to uncover modifiable risk factors across the lifecourse. Basic education is one promising candidate in improving cognitive outcomes. Based on observational evidence, The Lancet's recent dementia Commission concluded that $8 \%$ of dementia cases 
could be avoided by increased levels of basic education (Livingston et al., 2017). In the same vein, age-specific rates of incident dementia are falling (Ahmadi-Abhari et al., 2017), predominantly among those with at least a high school diploma (Chêne et al., 2016).

Although causal evidence is sparse, these findings are consistent with the hypothesis that increased population levels of education could reduce the growth in burden of cognition-related disease, and support economic adjustment to a changing demographic structure. With this in mind, the objectives of this study are two-fold. First, to provide new evidence on the extent to which schooling shapes cognitive function in later life. Second, to conduct a formal analysis exploring the channels driving these effects, paying particular attention to the role of occupation type and complexity.

Despite extensive observational research demonstrating that schooling is a correlate of cognitive outcomes throughout the lifecycle (Plassman et al., 1995), fewer studies are able to attach a causal to this association or the hypothesised underlying mechanisms. One approach, leveraged in this paper, is to exploit the substantial investments in publicly provided education occurring over the last century, notably the successive increases in the minimum age at which students can leave secondary school. These increases in the minimum schooling leaving age represent plausibly exogenous changes in schooling, and are widely employed to quantify both pecuniary and non-pecuniary returns to education (Harmon and Walker, 1995; Oreopoulos and Salvanes, 2011). The cohorts affected by these reforms are now ageing, providing an opportunity to explore whether the effects of schooling persist into later life.

The United Kingdom (UK) provides an especially informative laboratory to examine the causal effects of schooling. Two changes to the secondary school leaving age were enacted during the 20th century: in 1947 the minimum school leaving age was raised from 14 years to 15 years, and 1972 it was raised again to 16 years. These changes affected relatively large shares of the relevant cohorts. For example, the corresponding changes in the United States exerted a causal effect on only about $5 \%$ of the student cohort, compared with about 50\% and 25\% for the 1947 and 1972 reforms in the UK, respectively (Clark and 
Royer, 2013). Yet, the evidence base on schooling and cognitive function in the United Kingdom remains limited. For England and Wales, Banks and Mazzonna (2012) established positive effects of an additional year of schooling on aspects of cognitive function among the cohorts affected by the 1947 raising of the school leaving age. The findings are large in magnitude, raising the possibility that increased population education could function as a policy tool in fostering healthy ageing. However, the cohorts exposed to the 1947 reform grew up in unstable economic and political circumstances; their choice set and constraints they faced were vastly different from more recent cohorts. Whether these results are relevant in the current policy context, despite the changing nature of the work tasks, labour market participation, and health technology, remains unclear.

The first contribution of this study is to provide new evidence on the causal effect basic education on cognitive outcomes, using a Fuzzy Regression Discontinuity design to exploit the raising of the secondary school leaving age in 1972. This reform increased the minimum school leaving age from 15 to 16 years in England and Wales, and had a causal impact on the schooling choices of about one third of the affected cohort. The data employed is from Understanding Society (U.S.) — the largest household panel study in the United Kingdom. This data contains granular information on month-year of birth, allowing exact identification of exposure to the reform. Comparing the outcomes of observationally similar individuals exposed and unexposed to the reform—-born only months apart—yields credible estimates of the causal effects of the additional year of schooling.

One threat to the validity of this approach is confounding from secular trends in longevity and cognition: cohort-specific cognitive performance has been steadily increasing over the 20th-century (Flynn, 1987). This so-called Flynn effect may be influenced not only by investments in mass education during this time, but the changing nature of job-tasks to be more cognitively stimulating, improvements in nutrition, and the increasing proportion of women entering the labour force, which act as confounding factors (Skirbekk et al., 2013; Case and Paxson, 2009). To reduce concerns of this type of confounding, this study adjusts for birth cohort trends, and uses a small sample window-of just under three years 
either side of the reform date- to enhance the comparability of the treatment and control units. Additionally, sensitivity analyses are conducted using different covariates sets and sample window choices.

The second contribution is to explore the role of occupation choice as a key mechanism driving the effect of education on cognition. Despite many theories, less is known empirically about the channels which drive the education-cognition gradient. A number of hypotheses highlight the role of occupation type, especially with regard to occupational complexity, and the commonly cited "use-it-or-lose-it" hypothesis. This framework suggests mental stimulation may sustain brain function, supporting the idea that more cognitively stimulating activities stave off cognitive decline (Rohwedder and Willis, 2010). In a similar vein, proponents of the so-called "cognitive reserve" theories in neuropsychology have put forward education and occupation as key factors in increasing mental resilience, reducing the clinical manifestations of brain ageing (Stern, 2002).

This paper applies a methods from the casual mediation analysis literature to explore the role of occupation type as a key mechanism (Keele et al., 2015). To allow for potential endogeneity of occupation type-despite the absence of a credible second instrumentthe approach used relies on a type of conditional independence assumption for occupation choice (Yamamoto, 2014). While fundamentally untestable, this assumption is arguably credible in this application. Sensitivity analyses to additional confounders are conducted to provide support for this assumption.

The key findings include a local average treatment effect (LATE) of one additional year of schooling on working memory, ranging from one- to two-thirds of a standard deviation, depending on the sample and model specification employed. This effect is significant at at least the $10 \%$ level across a range of reasonable specifications, and is in excess of the Ordinary Least Squares (OLS) estimate of 0.15 standard deviations. While the OLS estimates shows a positive association between schooling and numeric ability and verbal fluency, there is negligible evidence for a causal effect on these outcomes.

Second, the effect size from the analyses of mechanisms indicate occupation type could 
explain up to $18 \%$ of the total effect of schooling on memory. However, the figures are very imprecisely estimated, and not statistically significant at conventional levels. Given the imprecision of the estimates, occupation's role in shaping cognitive outcomes remains an avenue for future study.

\section{Related literature}

\subsection{Non-pecuniary returns to schooling}

A recent empirical literature has used variation in minimum schooling laws to examine the lasting health and mortality effects of education, including mortality, self-assessed health, disability and health behaviours (recent reviews include Lochner (2011) and Mazumder (2012)). Fewer studies in this area have focused on cognitive outcomes. The first paper to exploit changes in the minimum school leaving age to explore cognition and mental outcomes was Glymour et al. (2008), who used state-level variation in the United States to obtain instrumental variable estimates of the effect of schooling on working memory and mental status among cohorts born between 1900 and 1947. These changes in mandated schooling yielded large improvements in performance on memory tests in old age, although no effects were detected for mental status.

Evidence from England and Wales exploited the 1947 school reform, which increased the minimum school leaving age from 14 to 15, Banks and Mazzonna (2012) found a positive effect of an extra year of schooling on the memory and executive function of older men. A number of studies have exploited both time-series and geographical variation in school leaving ages across Europe, using the Survey of Health, Ageing and Retirement in Europe (SHARE). Schneeweis et al. (2014) found a positive effect of an extra year of education on memory, and used the panel aspect to reveal evidence of a protective effect against declines in verbal fluency with age. In addition to increased memory scores among older men, Mazzonna (2014) also found reduced probabilities of depression and improved self-reported health. Analyses of potential mechanisms suggested an important role for 
working conditions in explaining these effects. These patterns are not limited to Europe and the U.S.: Huang and Zhou (2013) leveraged educational differences in primary school completion due to China's Great Famine, during 1959-1961, to assess education effects on cognitive outcomes in older ages. The results revealed a protective effect of cognition, especially episodic memory, of up to $20 \%$.

\subsection{Channels}

Given the large total effect size found in many studies, the protective effect of education of cognition is unlikely to be wholly a direct effect. More plausibly, education influences cognition indirectly, through the wider set of opportunities that education affords. A recent review of empirical studies identified self-reported health, biomarkers of physiological health (e.g., inflammation), cardiovascular disease and its risk factors, education and occupational trajectories, among others, as risk factors for age-associated cognitive decline (Deary et al., 2009).

A number of hypotheses provide a theoretical rationale for occupation choice as a key mechanism. First, "cognitive reserve" is a key framework from the neurological literature (Stern, 2002). Cognitive reserve is a hypothetical construct used to explain how, facing similar neurodegenerative changes, substantial variation is observed in cognitive ageing, and diagnosed cognitive impairment, across individuals. In other words, individuals do not experience the same declines in everyday cognitive functioning for a given decline in brain health. Cognitive reserve is the concept which is proposed to explain this resilience. Education and occupational complexity are often cited as important proxies for cognitive reserve, in addition to other "lifestyle factors" such as dietary habits and physical exercise.

Second, in the economics literature, a relevant framework is the dynamic model of the demand for good health proposed in Grossman (1972). This model describes the lifecycle accumulation and decumulation of a health stock, and how this relates to choices of occupation, activity and consumption. The implications of this framework can be extended more generally to a stock of cognitive capital: cognitive function in older ages is a 
component of health, which can be augmented by health investment and cognitive repair inputs, and depreciates with age. The role for education in the seminal Grossman model is to increase the efficiency of health production: those with more education enjoy a higher marginal productivity of a given health input.

Extending this framework, Muurinen (1982) and then Case and Deaton (2005) proposed an augmented model, in which education indirectly reduces the rate of depreciation of the health stock with age. Individuals are endowed at birth with stocks of health capital, human capital and financial capital, which are partially substitutable in producing earnings and utility. Those with less human capital will be restricted-via a constrained optimal choice - to occupations which rely more on manual effort or repetitive routine tasks, rather than cognitive skills, to produce earnings. The consequence of this choice is a increased rate of decline in functioning across the lifecycle. Another implication of the model is that the correlation between cognition and education is partly spurious. This framework predicts a higher health stock for a lower rate of time preference and higher initial stock of cognitive or financial assets. This is consistent with empirical regularity that at least $50 \%$ of variation in cognitive ability in old age (measured at about 80 years) is explained by cognitive ability in childhood Deary et al. (2009). This implication highlights the importance of addressing potential endogenity of education choices.

Focussing specifically on cognitive capital, Mazzonna and Peracchi $(2012,2017)$ extend this framework to analyse the age-profile of cognitive performance and how this changes after retirement. Empirical tests of the theory show cognitive function generally declines after retirement, as the monetary incentive to invest in this stock is reduced. However this effect importantly depends on occupation type: those employed in physically demanding jobs experience a short-run positive effect of retirement on cognitive function. Moreover, education is found to shape heterogeneity in both the level and age-related decline of cognitive function. Together these findings highlight the potential for occupation type as a mechanism in explaining variation in later-life cognitive function. 


\section{Data and setting}

\subsection{School reforms in England and Wales}

Many studies have leveraged the 1972 raising of the school leave to study the returns to education (e.g., Oreopoulos (2006); Clark and Royer (2013); Dickson et al. (2016)). The 1944 Education Act increased the minimum age pupils can leave secondary school from 14 to 15 years, enacted from April 1st 1947; this Act also conferred powers to raise the minimum school leaving age again to 16 years. In March 1972, it was decided that the minimum school leaving age would be raised to 16 years for school cohorts beginning on the 1st of September 1972 (Woodin et al., 2012). This change to 16 years affected birth cohorts of pupils born from the 1st of September, 1957, onward. The 1972 change, aside from being more recent, was enacted in less unstable times- the cohorts exposed to the 1947 change were were affected by the aftermath of the Great Depression, and effects of the World War. The second, 1972, school reform is exploited in this paper. Considering this more recent reform may shed light on whether the results from previous studies using the 1947 change are generalisable, given the particularities of the context faced by those earlier cohorts.

In addition to an extra year of school completed, the 1972 change led to greater rates of completion of formal qualifications; many more students stayed until the end of their 16th school year to obtain "O-level" qualifications. This increase in the probability of gaining a qualification is important. Dickson and Smith (2011) exploit the Easter Leaving Rule_-an institutional rule providing exogenous variation in qualification attainment-confirming that some of the observed wages returns to an extra year of schooling in 1972 were due to the increase in qualifications, rather than solely the length of time in school.

\subsection{Data sources}

The dataset employed is Understanding Society (US), a panel study of households in the United Kingdom (McFall, 2013a; Institute for Social and Economic Research and Nat- 
Cen Social Research, 2015), the successor study to the British Household Panel Survey (BHPS). It commenced in 2009 as a representative probability sample of approximately 40,000 households. Participants are interviewed annually, but each wave of data collection spans 24 months (therefore the survey waves are overlapping and comprise approximately two years of data collection). The "total sample" comprises multiple subsample components: the main General Population Sample (GPS), continuing BHPS members, and the Ethnic Minority Boost (EMB) subsample. Wave 3, beginning on 7th January 2011 and ending on the 12th July 2013, included a Cognitive Ability module which measured self-rated memory, performance on tests of word recall, numeric ability and verbal fluency measures (McFall, 2013b). Wave 3 has a cross-sectional response rate of 61.3\%. Throughout the analyses the survey weights provided with the data were employed, to allow for the possibility of endogenous sampling design and response probabilities. The weights adjust for the complex survey design, and combined probabilities of being selected into the BHPS, GPS and EMB and continuing to Wave 3 of the survey.

\subsection{Variable construction}

\section{Years of schooling and cognitive outcomes}

The measure of schooling employed is the report of years of secondary schooling completed. This is derived from the schooling question asking "How old were you when you left school?". Then years of schooling is constructed as the age the respondent reports leaving school minus five.

Episodic memory-retrieving memories associated with specific events-was measured by performance on an immediate and delayed word recall test. Memory is an important early indicator of potential cognitive impairment, and word recall tests are used in cognitive impairment screening tests (Kim et al., 2014). A list of 10 words are read aloud by the computer, the respondent is to repeat these words in any order and the number correctly recalled is recorded by the interviewer. This procedure is repeated (about 
5 minutes) later in the module to measure delayed recall. Immediate and delayed word recall scores are highly correlated with clinical dementia diagnoses (Wu et al., 2013). The number of words correctly recalled in each test were summed, to create a variable (Word Recall) ranging from 0 to 20.

The Serial 7 Subtraction test is a component of clinical screening instruments for cognitive impairment (i.e,., the Mini Mental State Examination (Crum et al., 1993) and the Cambridge Mental Disorders of the Elderly Examination (Roth et al., 1986)). In the Serial 7 test, respondents are asked to begin at 100 and subtract 7, five times. After each subtraction, the respondent is again prompted by the interview to "take 7 away from that?". The number of correct answers was summed to create a variable ranging from 0 to 5 .

The Verbal Fluency test asked respondents to name as many animals as possible in one minute. In addition to testing semantic memory, this tests also executive function as, to perform well, it requires some level of abstract thinking and mental flexibility within a time limit. The test is from the cognitive assessment component of the Cambridge Mental Disorders of the Elderly Examination, an interview procedure for the diagnosis and measurement of dementia in the elderly (Roth et al., 1986), and has been successfully been employed in extensions of the MMSE (Kim et al., 2014). The number of animals listed ranges from 0 to 71 .

The Numeric Ability test assessed ability to solve "every day" numerical problems. The Numeric Ability test asks the respondent five questions of increasing complexity, for example, the first question is as follows: "In a sale, a shop is selling all items at half price. Before the sale, a sofa costs $£ 300$. How much will it cost in the sale?’. The number of questions correctly answered was summed to have a range of 0 to 5 .

The distributions of the raw scores are presented in Appendix A. The continuous measures, Word Recall and Verbal Fluency, were standardised by subtracting the sample mean and dividing by the sample standard deviation, to faciliate interpretation and comparability with previous studies. The Serial 7 Subtraction and the Numeric Ability tests were dichotomised to create a binary variables. Subtraction takes the value 1 for respondents 
with 5 correct answers to the Serial 7 Subtraction, and zero otherwise. Numeracy takes the value 1 for respondents with 4 or 5 correct answers to the Numeric Ability test, and zero otherwise.

\section{Occupation variables}

The first measure employed is the five-class National Statistics Socio-economic Classification (NS-SEC) occupational classification. The five-class NS-SEC groups occupations defined by the Standard Occupation Classification into five categories: 1) Semi-routine; routine; never-worked and long-term unemployed; 2) Lower supervisory and technical occupations; 3) Small employers and own account workers; 4) Intermediate occupations; 5) Higher professional; large employers, higher managerial and administrative occupations. The ordering of NS-SEC captures information both on the tasks used in the occupation, as well as the employment relation: how much autonomy a worker has in their job.

The NS-SEC is available for both the first job chosen after leaving secondary school, and the current job (or previous job, if the respondent is currently out of the work). The chief focus is on the current, or most recent, occupation, which will capture effects associated with the so-called "use-it-or-lose-it" hypothesis: continuing to engage in a stimulating occupation maintains cognitive reserve and stave off cognitive decline. The first job is of interest as mechanism because the activity chosen immediately after secondary school is especially amenable to policy intervention. For instance, in the UK context, a current policy development has increased the minimum "participation age", for which young people must remain in education or training, from 16 years to 18 years. This initial start may have longer run implications for labour market trajectories.

Previous occupation was disproportionately missing among those reporting they were long-term sick or disabled, or unemployed. For this group, information from the US employment history module was used to ascertain their activity. Respondents to the US report an employment history of their economic activity status (e.g., full-time work, part-time, unemployed, receiving government benefits, etc.) from when they first left full-time education until their current spell. For those who did not report a current or previous labour 
market status, individuals who also reported being out of the paid work for at least $50 \%$ of their potential working life were coded as NS-SEC category 1 (Semi-routine; routine; never-worked and long-term unemployed).

In addition to the occupation type of first and current job, a final measure of occupation type relates directly to the usage of specific skill types, employing occupational skills profiles developed by Dickerson et al. (2012). Dickerson et al. (2012) have matched the UK SOC 2010 codes with the US Occupational Information Network (O*NET), a database characterising the skills, abilities, work characteristics of occupations. The O*NET questionnaire is completed by workers and external job analysts. Over 250 questions are asked about job characteristics, or descriptors, arranged into the following domains: education and training, knowledge, skills, abilities, work activities, work context and work style. For each descriptor, both the level and importance of that item are elicited. The individual responses are averaged within occupations. Therefore, for each individual, they do not necessarily reflect the skills actually used in a job.

The literature on occupation, education and cognitive outcomes has raised the hypothesis that especially demanding or complex mental tasks may play an important role in maintaining cognitive performance (Fisher et al., 2014). One specific example of these types of complex skills (chosen partly due to data availability) are those used in what are commonly characterised as STEM occupations. These roles require substantively complex, technical expertise-involving logic, reasoning and numeracy. Examining the role of these specific types of skills contributes to the literature assessing the role of skills type in determining cognitive ageing, and provides a useful complement to the occupation type measures described above.

The measure of STEM-skill usage, henceforth termed technical skill, uses variables from the Abilities and Skills from the matched O*NET data (the questions in the Ability and Skill domains were filled out by external job analysts, rather than the job incumbents themselves). This measure was matched to the occupation of first job after leaving school. ${ }^{1}$

\footnotetext{
${ }^{1}$ At the time of writing, the current occupation variable in the US was coded as SOC2000. Only when respondents switched to a new job, the new job was coded as SOC2010. Therefore it was not possible to
} 
The Abilities items used are: deductive reasoning; information ordering; mathematical reasoning; number facility. The Skills items are: mathematics; science; technology design; programming. For each item, there is a variable rating the level of each decriptor used in the job, and its importance. The average of the level and importance variables across the Skills and Abilities items identified above are used as a simple continuous measure, where a higher value indicates greater usage of these skills_-on average-in an occupation.

\section{Analytical sample}

All three subsamples of the US were employed: the General Population Sample, continuing BHPS participants, and the Ethnic Minority Boost sample. Survey weights were employed throughout the analyses, which weights adjust for unit non-response- the combined probabilities of being selected into the BHPS, GPS and EMB and continuing to Wave 3 of the survey — and the complex survey design.

Since the location of school was not available among the cohorts considered, it was not possible to ascertain whether respondents completed their schooling in England or Wales, rather than Scotland or Northern Ireland. In order to restrict the sample to individuals who completed their schooling in areas exposed to the reform as best as possible, those who were born in England or Wales were selected for analyses. Observations which had missing or unavailable information on place of birth were assumed not to be born in England or Wales.

The preliminary descriptive statistics use a sample of respondents born with a window of 5 years either side of date determining exposure to the school reform (01, September, 1957). The sample for the OLS and RD estimation uses a smaller window, determined by an optimal bandwidth-selection prodecure. The main analyses examines the role of different measures of occupation choice in driving the effect of schooling on cognitive outcomes. For these analyses, a restricted sample was used, comprising respondents who reported complete data for all three occupation measures. Regression analyses did not detect statistically differences between this subsample and the complete sample across a set match the $\mathrm{O} *$ NET measure to complete data on current occupation. 
of pre-determined characteristics, including age, gender, month-of-birth, interview date, region and parental education. There were differences in the sample of origin (BHPS, GPS, EMB). This is because first occupation after leaving school, and skill usage in first occupation, are disproportionately missing among the continuing BHPS sample due to the survey design; the missingness is related to survey routing rather than personal characteristics. This provides support for these missing value to be ignorable (missing-at-random).

However, for the current occupation variable, the missingness patterns may still be related to the unobserved value of occupation type and cognitive outcomes, even after conditioning on the observed covariates. Those how do not report a current, or previous occupation for those out of work, may be systematically different from those who doplausibly, less engaged and in lower skilled work. Therefore the likely direction of the bias would be that resulting estimates would represent a lower bound effect, if indeed the sample used is on average more healthy and engaged than the general population. For analyses which do not require the occupation variables-i.e., sensitivity analyses for the main effect of schooling on cognitive outcomes - the full sample was employed (i.e., including those who did not report an occupation or labour market history) to examine the robustness of the total effect of these restrictions.

\subsection{Descriptive statistics}

Table 1 shows the years of schooling reported before and after the raising of the school leaving age (RoSLA), for men and women respectively. Evidently the reform induced students to stay in school until age 16 years. In line with previous studies there are few spillover effects into the higher levels of schooling (Chevalier et al., 2004). There is some non-compliance; after the reform, some students report leaving when aged 15 years. As noted in Clark and Royer (2013), this is likely to be due to the institutional feature that in their sixteenth year of school, students are able to leave school in the summer exam period (May to mid-June) upon completion of the O-level exam. For summer-born students, this mean some may still be aged 15 years when they complete their exam and leave school. 
Table 2 presents summary statistics for key variables for respondents within 5 years of the treatment threshold (birth date 01, September, 1957), for the pooled sample and separately by gender (histograms of these outcomes are presented in Appendix A). Men have higher average scores on the Numeracy, Serial Subtraction tests and Word Recall tests than women; women on average have a very slightly higher score for Verbal Fluency. Figure 1 shows how the cognitive outcomes considered evolve with age by years of education, comparing those who left at age 15 years with those who left at age 16 years. For all outcomes, there are mean differences by schooling level across all ages. Word Recall and Verbal Fluency exhibit marked declines by age, which are pronounced from approximately age 40 years.

Figures 2 and 3 show sample means of each outcome by values of month-of-birth cohort, for respondents born within 5 years of the treatment threshold (01, September, 1957) who left school before 17 years of age. A quadratic trend in birth cohort was fitted to underlying data to show the global trends in the data. Figure 2 plots mean years of school by birth cohort relative to the 1 st September 1957 cut-off. The discontinuity in mean years of schooling is evident both in the full sample, and also when the sample is restricted to those who left school at age 16 or earlier.

\section{Empirical approach}

A Fuzzy Regression Discontinuity (FRD) design (Imbens and Lemieux, 2008) was employed to exploit variation in schooling induced by the reform. RD is predicated on treatment, for individuals $i=1, . ., N$, being assigned by the value of a continuous covariate, $R_{i}$, falling on either side of a fixed cutoff $c$. In this application $c$ is the pivotal birth cohort of 01 , September, 1957 . This cutoff induces a discontinuity in the conditional probability of receiving the treatment given $R_{i}$ - but not necessarily a jump from 0 to 1 . Let $Z_{i}$ denote exposure to the reform, $\left(Z_{i}=1\left[R_{i} \geq c\right]\right)$, where $1($.$) is the indicator function, and$ the treatment is an additional year of schooling. Let $Y_{i}(1)$ and $Y_{i}(0)$ denote the potential 
cognitive outcomes experienced in the presence and absence of the treatment respectively. The FRD estimand of interest is the following:

$$
\tau_{F R D}=\frac{E\left[Y_{i}(1) \mid R_{i}=c\right]-E\left[Y_{i}(0) \mid R_{i}=c\right]}{E\left[D_{i}(1) \mid R_{i}=c\right]-E\left[D_{i}(0) \mid R_{i}=c\right]}
$$

Assuming the reform only changes behaviour in one direction (monotonicity), then the FRD estimator yields an average treatment effect at the cut-off among the sub-population of compliers (i.e., those who were causally induced to take an extra year of schooling, which otherwise they would not have taken). In this case, the FRD treatment effect is the ratio of the sharp RD effect and the average effect of the reform on treatment, as in Equation (2) (Hahn et al., 2001).

$$
\tau_{F R D}=\frac{\lim _{r \downarrow c} E\left[Y_{i} \mid R_{i}=c\right]-\lim _{r \uparrow c} E\left[Y_{i} \mid R_{i}=c\right]}{\lim _{r \downarrow c} E\left[D_{i} \mid R_{i}=c\right]-\lim _{r \uparrow c} E\left[D_{i} \mid R_{i}=c\right]}
$$

This framework also extends to the case of a multi-valued measure of years of schooling, in which the compliers are defined as those induced to take at least $d$ years of schooling when otherwise they would have taken fewer than $d$ (Angrist and Imbens, 1995)). In that case, the effects computed are an average of the per-year treatment effects associated with each additional year of schooling, weighted by the proportions of compliers at each level of schooling. However, in this application there is little weight placed on the schooling levels above 16-the treatment effect is mainly informed by differences in outcomes on the 15 to 16 years margin. The main analyses presented in this paper are for a binary treatment, equal to zero if pupils left school at age 15 years, and one if they left at 16 years of age, and missing for those who stayed on to 17 years or older. This is also to facilitate the computation and interpretation of the analyses of mechanisms in the subsequent section, which is more straightforward with a binary treatment. Results with a multi-valued treatment are presented in Appendix B.

Using a uniform kernel, and the same bandwidth $h$ for the outcome and treatment equations, leads to a numerical equivalence between the FRD estimator and the Two-Stage 
Least Squares (2SLS) estimator (Hahn et al., 2001). Taking this approach, the parameters of the equations described in Equations (3) and (4) were estimated using 2SLS. Let $Y_{i}$ denote the cognitive outcome observed for individual $i$. $f\left(R_{i}-c\right)$ comprises the centred running variable, interacted with the reform dummy. The vector $X_{i}$ includes pre-treatment covariates, and $u_{i}$ and $v_{i}$ are idiosyncratic errors.

The estimating equations are described as follows:

$$
\begin{aligned}
& Y_{i}=a_{o}+a_{1} \hat{D}_{i}+f\left(R_{i}-c\right)+X_{i}^{\prime} a+u_{i} \\
& D_{i}=\gamma_{o}+\gamma_{1} Z_{i}+g\left(R_{i}-c\right)+X_{i}^{\prime} \gamma+v_{i}
\end{aligned}
$$

To select a data-driven optimal bandwidth, the implementation of the MSE-optimal bandwidth developed in Calonico et al. (2016) was employed, which accounts for the fuzzy design and clustering of the data due to the discrete running variable (Bartalotti and Brummet, 2016). This was combined with a sensitivity analyses through a consideration of a range of bandwidths. The running variable is month-year of birth. This allows a comparison of units very close to the treatment cut-off. However this measurement is still a discretisation compared, as a more granular measurement of assignment (e.g., dayof-birth) was not available in the data. The standard errors were clustered by month-year of birth to account for group-level variation induced by the discrete nature of the running variable. This relies on a model in which the fitted function, through the discrete running variable, approximates the true continuous function, and the consequent specification errors are random and identical (Lee and Card, 2008).

In very small sample windows around the reform date it is more credible that the reform, as a local instrumental variable, is plausibly exogenous without conditioning on further covariates. Other discontinuities exactly coincident with the RoSLA are unlikely. In this case, the purpose of the covariates is to increase the precision of the estimates by reducing residual variation. In larger sample windows, the concern remains that there may 
be confounding of education level and cognitive function based on unobservable functions of birth cohort. For example later cohorts, exposed to the reform, may have experienced more favourable conditions in early childhood, and have more educated parents, than the earlier pre-reform cohorts. Although these trends are unlikely to be discontinuous at the treatment cut-off, they may still be picked up in larger sample windows. Therefore, this concern motivates adjustment for potential confounding variables which may capture any such effects.

The covariates included in the RD models presented in Table 3 are: a quadratic term in age, dummy variables indicating gender, interview month, interview year (because the US survey waves span approximately two years).

In further sensitivity analyses (Appendix B), month-of-birth dummies were added as covariates. The rationale for considering month-of-birth is to capture any seasonality effects: systematic variation in month-of-birth by family background which could also be related to later education, health and cognitive outcomes (Buckles and Hungerman, 2013). Additionally, since the implementation of the 1972 reform coincides with the start of the school term, exposure to the reform will coincide with any age-in-grade effects, and therefore be correlated with schooling and, potentially, cognitive outcomes.

\subsection{Channels}

The FRD analyses yields a total treatment effect (among compliers). Since any effects of schooling on cognitive function could operate either directly or indirectly, though subsequent opportunities and choices that schooling affords, this section tests a number of hypothesised underlying mechanisms. One approach to answering this question is to employ a so-called mediation analysis. Mediation analysis aims to empirically disentangle the causal mechanisms through which a treatment exerts its effect on the outcome. A mediator is a variable which lies on the causal pathway between treatment and outcome. In this framework, a total effect may be decomposed into two components: an indirect effect, operating through the mediator of interest, and a direct effect operating through all other 
unmodeled intermediate variables. Recent literature has clarified the assumptions under which these mechanisms are identified (see, for instance, Imai et al. (2011); Huber et al. (2015); Keele et al. (2015) for recent reviews and applications). The focus has been on non-parametric identification, leading to the development of a range of flexible estimation approaches.

This paper employs the results developed in Yamamoto (2014), who shows thatgiven certain assumptions - the LATE can be decomposed into components explained, and unexplained, by a mediator of interest. To do so, Yamamoto (2014) develops a proof of nonparametric identification of average causal mediation effects among compliers, and proposes a flexible estimation approach to implement the method. This section draws on that paper to briefly outline the framework.

Let $D_{i} \in\{0,1\}$ denote the level of treatment selected by individual $i$, where $i=$ $1, \ldots, N . D_{i}=1$ if a pupil leaves school at 16 , and $D_{i}=0$ if a pupil leaves at 15 years. $Z_{i}$ denotes the observed value of the instrument. $D_{i}\left(Z_{i}\right)$ indicates the potential treatment state for individual $i$; the treatment they would select depending on the value of the instrument. The observed schooling level can then written as $D_{i}=D_{i}\left(Z_{i}\right)=Z_{i} D_{i}(1)+\left(1-Z_{i}\right) D_{i}(0)$. Let $M_{i}$ and $Y_{i}$ denote observed mediator and observed cognitive outcomes, respectively, and $X_{i}$ a vector of observed pre-treatment covariates. $M_{i}(d)$ indicates the potential mediator state, depending on the level of schooling chosen. $M_{i}(1)$ is the value of the mediator chosen under treatment level 1 , and $M_{i}(0)$ is the value the mediator would take under treatment level 0 . The potential cognitive outcomes are denoted $Y_{i}(d, m)$, depending on treatment and mediator.

The local average treatment effect, incorporating the choice of mediating variable, can be written as follows:

$$
\tau=E\left[Y_{i}\left(1, M_{i}(1)\right)-Y_{i}\left(0, M_{i}(0)\right) \mid D_{i}(1)=1, D_{i}(0)=0\right]
$$

Varying the treatment exogenously, but fixing the mediator at the its potential value for 
$d \in\{0,1\}$ yields the average direct effect among compliers: the Local Average Natural Direct Effect (LANDE).

$$
\zeta(d)=E\left[Y_{i}\left(1, M_{i}(d)\right)-Y\left(0, M_{i}(d)\right) \mid D_{i}(1)=1, D_{i}(0)=0\right]
$$

Fixing the treatment at $d \in\{0,1\}$, but varying the mediator to its potential values under treatment and non-treatment yields the average indirect effect among compliers: Local Average Complier Mediated Effect ( $L A C M E)$.

$$
\delta(d)=E\left[Y_{i}\left(d, M_{i}(1)\right)-Y_{i}\left(d, M_{i}(0)\right) \mid D_{i}(1)=1, D_{i}(0)=0\right]
$$

The LACME and LANDE, defined on opposing treatment states, sum to the LATE. ${ }^{2}$ $\delta(1)$, for example, represents the difference in two potential outcomes: $Y_{i}\left(1, M_{i}(1)\right)$ represents the observed cognitive outcome if pupil $i$ stays at school until 16 years; $Y_{i}\left(1, M_{i}(0)\right)$ represents the cognitive outcome under a counterfactual scenario, in which the pupil again stays at school until 16 years, but then selects the occupation they would have chosen if they had left at 15 years. The difference between these two potential outcomes is the effect of the change in the mediator induced by the treatment, fixing the direct effect of the treatment.

Conversely, $\zeta(1)$ represents the difference in potential cognitive outcomes between leaving school at 15 years and 16 years, holding occupation constant at the level which would be chosen after leaving at 16 years. Therefore, this is the portion of the treatment effect not transmitted through the mediator. The notation $\zeta(d)$ and $\delta(d)$ suggest the possibility of interaction between mediator and treatment. ${ }^{3}$

\footnotetext{
${ }^{2}$ The following should be conditioned on being a complier; notation omitted for brevity.

$L A T E=E\left[Y_{i}\left(1, M_{i}(1)\right)-Y_{i}\left(0, M_{i}(0)\right)\right]$

$=E\left[Y_{i}\left(1, M_{i}(0)\right)-Y\left(0, M_{i}(0)\right)\right]+E\left[Y_{i}\left(1, M_{i}(1)\right)-Y\left(1, M_{i}(0)\right)\right]=\zeta(0)+\delta(1)$

$=E\left[Y_{i}\left(1, M_{i}(1)\right)-Y\left(0, M_{i}(1)\right)\right]+E\left[Y_{i}\left(0, M_{i}(1)\right)-Y\left(0, M_{i}(1)\right)\right]=\zeta(1)+\delta(0)$
}

${ }^{3}$ For example, this would mean that the indirect effect — the effect of schooling-induced occupation choice 
$\zeta(d)$ and $\delta(d)$ are counterfactual quantities, since we do not observe any individual with, for instance, the value of the mediator they would have selected under the counterfactual treatment. Given the counterfactual nature of the effects of interest, identification of causal mechanisms requires accounting for potential endogeneity of not only the treatment, but also the mediating variable.

The assumptions required to identify the LANDE and LACME include, first, an exclusion restriction for the instrument and monotonicity, required in a standard instrumental variable analysis. The second assumption is the so-called local sequential ignorability assumption (described in Equations 8 and 9). The first part of this assumption, described Equation 9, requires conditional independence of the instrument with respect to both the potential cognitive outcomes and potential mediator states, which is satisfied by a valid instrument for schooling. The second component, Equations 8, requires the mediator to be conditionally independent of the potential cognitive outcomes, given the treatment (years of schooling) and pre-treatment covariates, among the compliant subpopulation.

$$
\begin{gathered}
Y_{i}(d, m), M_{i}\left(d^{\prime}\right), D_{i}(z) \perp Z_{i} \mid X_{i} \\
Y_{i}\left(d^{\prime}, m\right) \perp M_{i}(d) \mid D_{i}=d, X_{i}, \text { type }=\text { complier }
\end{gathered}
$$

In this application, this conditions will be satisfied if we believe that there is no unobserved variable systematically influencing both occupation choice and cognitive function, within cells defined by both education level and the pre-treatment covariates, among the compliers to the reform. In contrast to the choice of education level, it is more difficult to think of specific confounding variables which would play this role. Sensitivity analyses were conducted to potential confounders (region, parental education, month-of-birth - results available by request). Additional maintained assumptions include the absence of any confounders of the mediator and outcome which are themselves caused by the treatment on average cognitive outcomes_could differ between those who leave at 15 and those leave at 16 years. 
(so-called intermediate confounders).

The estimator employed for the LANDE and LACME is described here in Appendix C. It is expressed as functions of conditional expectations (and densities) of the outcome, treatment and mediator. The estimation procedure involves fitting flexible predictive models to the treatment, mediator and outcome. The relevant conditional expectations, or conditional densities, are then computed and plugged into the respective formulas (in Appendix C). Standard errors were obtained via bootstrapping, with 1000 replications.

A linear model, estimated using least-squares, was employed for the treatment, the continous mediator (intensity of technical skills used in first job) and the outcome (Word Recall). The covariates in the treatment equation were the instrument and pre-treatment covariates; the covariates in the mediator equation were the treatment, instrument, an interaction between treatment and instrument, and pre-treatment covariates; in the outcome equation the covariates were main effects and interactions between the mediator, treatment and instrument, and pre-treatment covariates.

An ordered probit model was employed for categorical mediators (occupation type), conditioning on treatment, instrument, an interaction between treatment and instrument, and the pre-treatment covariates. The pre-treatment covariates included were: a linear trend in month-year of birth cohort (interacted with the reform dummy), indicators for gender, interview month, interview year, and age-at-interview.

One caveat of the analyses presented here is that each of the intermediate variables are treated as independent from each other: the LANDE and LACME are computed separately for each mediator. This does not allow for causal dependence between the mediators. Conceptually, the purpose is to examine these variables as alternative measures of the same potential channel, rather than the intention being to model them jointly as a system and disentangle the distinct role of each mediator. Extending the framework to multiple dependent mediators would require more complex sets of potential outcomes: defining the potential mediator values in response to the choice of the other mediators, and the imposition of further assumptions about confounding between mediators themselves (e.g., 
see Park (2015)). This type of extension is left for further work.

\section{Findings}

This section considers the findings from the OLS and RD specifications, sensitivity analyses, and an examination of the channels through which these effects operate.

\subsection{OLS and RD results}

Table 3 reports OLS and RD results of the effect of schooling on Word Recall, Numeric Ability, Verbal Fluency and Subtraction, respectively. The sample used in this table has two key restrictions: 1) respondents who left school before the age of 17 years (this group represents the bulk of the compliers), 2) respondents who have complete data for each of the three occupation type measures (for comparability with the subsequent analyses of mechanisms). Estimates of the effects of schooling on cognitive outcomes for the unrestricted sample are presented in Table 7.

The findings in Table 3 show a positive association between years of schooling and each cognitive outcome. An additional year of schooling is associated with a 0.15 standard deviation increase in Word Recall, 0.18 standard deviation increase in Verbal Fluency, 17 percentage point increase in Numeric Ability and a 10 percentage point increase in Subtraction. These results corroborate those found in other literature: the positive correlation between education and cognitive outcomes persists into later life. However, these findings may not necessarily represent causal effects, due to omitted variable bias. The RD specification addresses this issue by exploiting plausibly exogenous variation in schooling.

Table 3 shows the RD estimates using a linear specification in the running variable (month-year of birth cohort). A discontinuity in average years of schooling is present at the reform cut-off. This is reflected in the first-stage results: the average difference in years of schooling between those exposed and unexposed to the reform is between 0.33 and 0.44 , depending on the sample window used. The RD estimates exploit this jump 
in years of schooling. Computed at the optimally-selected bandwidth, 30 month-year of birth cohorts, the RD estimates show that an extra year of schooling is associated with a statistically significant 0.53 standard deviation increase in Word Recall. Considering the two components of the word recall measure separately, i.e., delayed and immediate recall, the effect size is larger for delayed recall (data not shown). Considering Verbal Fluency, the effect size is 0.15 standard deviations, but not statistically significant at conventional levels. Again these estimates are derived from a small sample window, comprising those born 30 months either side of the threshold.

Although there is a positive association between schooling and the two measures relating to numeracy—Serial 7 Subtraction and Numeric Ability—shown in the OLS estimation results, this is not reflected in the RD specifications. The effect size is similar for Numeric Ability, an additional year of schooling is associated with a 17 percentage point increase the probability of successfully answering 4 or 5 questions out of the 5 numeric ability questions asked. For Serial Subtraction, the sign of the effect switches, with an effect size of minus 14 percentage points. These effects are not statistically significant at conventional levels. This may be due to ceiling effects: clustering toward the top of the distribution of performance on these tests, such that the measure may have little ability to distinguish between moderate and high functioning. Treating these variables as continuous variables, rather than dichotomising them, produces similar results.

Education may affect men and women differently; men and women have both different labour market trajectories and different levels of cognitive function in older ages. Table 7 in Appendix B reports results from the same sample and specification used in Table 3, now separately by gender. At the optimal bandwidth, no statistical evidence is detected for a differential association between schooling and the cognitive outcomes by gender. The size of the treatment effect by gender does vary by bandwidth and the sample definition, however the difference in estimates between men and women in other sample windows is also not statistically significant. Given the small sample sizes in the gender subgroups, a more complete examination of gender differences is not pursued here. 


\subsubsection{Sensitivity analyses}

An important choice is the choice of sample window (the bandwidth). To assess the sensitivity of the findings to a range of bandwidths, the point estimates and confidence intervals by bandwidth were examined. For instance, Figure 4 plots the treatment effect on each cognitive outcome, and 99\%, 95\% and 90\% confidence intervals, for a range of bandwidths. The optimally-selected bandwidths are indicated by vertical lines. There is variation in the effect size by bandwidth: for Word Recall, the treatment effect ranges from a minimum of 0.24 to a maximum of 0.74 across bandwidths from two to five years. This shows that the estimates do vary by choice of sample, however they remain positive and generally significant at least the $10 \%$ level across a reasonable range of bandwidths. This is in contrast with the other outcomes, where the effects size oscillates around zero and no statistically significant effects are detected across all values of bandwidth choice.

These plots are presented again in Appendix B, Figure 6, using a local quadratic, rather than local linear, RD specification: the local quadratic specification has the running variable included as a quadratic, rather than linear, term. These results corroborate those from the simple linear case, and show the results are robust to a more flexible specification of the birth cohort trends. Table 7 and Figure 7 report results - the causal effect of years of schooling on each cognitive outcome-for the full sample with no restrictions (i.e., including those who left school at ages 17, 18, or 19 years, and including those who did not report data for the occupation variables). The main findings are qualitatively similar to those in the restricted sample, although the effect size are lower: one additional year of schooling leads to a 0.32 SD increase in Word Recall. Again, negligible evidence is detected for effects on the other cognitive outcomes. Figure 7 also reports on a specification with month-of-birth dummies as covariates, demonstrating that the results are similar with this addition. The size of the estimates of the effects of schooling on cognitive outcomes do vary with the sample definition, covariate choice and bandwidth, and are not statistically significant in all specifications examined. However, taken as a whole, the positive, statistically significant, effects across a range of reasonable bandwidths and sample definitions 
provides a strong case for the veracity of the main results.

The corresponding findings in Banks and Mazzonna (2012), who exploited the 1947 raising of the school leaving age from 14 to 15 year, include a causal effect of an additional year of schooling on Word Recall, which ranges between about one-fifth of a standard deviation to two-thirds of a standard deviation among men, and between one-fifth of a standard deviation to two-thirds of a standard deviation among women. These effects tended to be statistically significant at at least the $10 \%$ level in the sample restricted to those who left school when aged 16 years or fewer. Similar to the present paper, the variation in these results in Banks and Mazzonna (2012) comes from different bandwidth choices and sample definitions. Their preferred estimates are an effect of half a standard deviation among men, and 0.4 among women. For Verbal Fluency, the effect sizes are similar to that for Word Recall among men, and statistically significant at the $10 \%$ level. Among women, no evidence was detected for any effects on Verbal Fluency — the effects oscillated around zero and were not statistically significant.

The 1947 reform had large effects on staying-on rates, inducing about $50 \%$ of the affected cohort to remain in school to 15 years, rather than 14 years. Based on an diminishing returns to education argument, we may have expected the 1972 reform to yield lower cognitive returns compared with the earlier reform. Indeed, the present study does not detected any causal effect on Verbal Fluency. However, the effects on Word Recall are within a similar range to the findings in Banks and Mazzonna (2012). These results suggest the cognitive returns to increasing basic education have not been exhausted, for an outcome which is especially relevant for the onset of cognitive impairment. The estimated LATE is a policy-relevant parameter: in the UK, the participation age (in education or training) has now been increased from 16 years to 18 years, and again the group affected by this reform will share many characteristics with those affected by the 1972 reform: lower parental education, and lower academic ability. Therefore it may be reasonable to expect this cohort to benefit from these long-run cognitive gains from staying in education or training. 


\subsection{Channels}

The RD results revealed a positive causal effect of schooling on Word Recall. This section reports on the analyses of potential underlying mechanisms.

Table 5 examines the effect of an additional year of schooling on the intermediate outcomes. It shows the results of three models: the causal effect of an additional years of schooling on occupation type of the first job after leaving school, occupation type of the current job, and technical skill usage. The first two specifications, which have categorical outcomes, are estimated via Maximum Likelihood using the cmp package in Stata. The third specification, with a continuous outcome, was estimated using 2SLS. The first column in Panel (a) shows the effect of taking 16, rather than 15 years of schooling on the average probability of choosing each occupation type in one's first job. An additional year of schooling leads to statistically significant reduction in the probability of taking a routine or semi-routine occupation immediately after leaving school, of 11 percentage points. On the other end of the spectrum, an additional year of schooling leads to an average of a 4 percentage point increase in the probability of taking a managerial or professional job immediately after leaving school.

As shown in Panel (b), the effects on current occupation (measured toward the end of working life) are smaller in magnitude: for instance, an additional year of schooling leads to 16 percentage point reduction in the average probability being in a routine or semiroutine occupation. Panel (c) presents the results of a 2SLS regression examining the effect of schooling on the extent of technical skills used in first job after leaving school. An additional year of school increases the index of technical skills used in first job out of school by 1.72 units, the equivalent of half of a standard deviation.

Table 6 presents the results of the analysis of causal mechanisms, assessing whether these initial effects of schooling on occupation type translate into improvements in cognitive function. The table presents the LATE, the LACME (portion of the LATE explained by the mediator) and LANDE (remaining portion of the LATE, explained by all other unmodeled intermediate variables). These quantities are calculated separately to test the role 
of three alternative mediator variables-first occupation type, current occupation type, technical skills-presented across the three columns.

The indirect effects among compliers are presented separately depending on whether the treatment status is fixed at the control or treatment status (leaving school at 15 years or 16 years). This allows for an interaction between treatment and mediator; the size of the indirect effect can differ by treatment level. The table shows that occupation type of first job explains $0.0 \%$ of the LATE for the controls, and $0.02(3.8 \%)$ for treatment, although these are estimates are very imprecise and not significant at conventional levels. For the occupation type of current job, these figures are both $0.06(11.3 \%)$. Considering the level of technical skills used in the first job, the size of the indirect effect is negligible at 0.00 for the controls, and 0.10 (18\% of the total LATE) for treatment. These models were fit to the sample window defined by the optimally-selected bandwidth of 30 month-year of birth cohorts. The size of the estimates vary as the sample window is modified, however the qualitative conclusions remain the same. The findings are also robust to the addition of further covariates, specifically region, parental education and month-of-birth (results available by request).

The positive indirect effects in both models suggest occupation choice may play a role, consistent with theory-however the estimates of the indirect effect are very imprecisely estimated. This is to some extent due to the nature of the estimation method, which is less efficient than a parametric approach, as can be seen in comparing the precision of the LATE estimated by 2SLS with the nonparametric method. In terms of effect size, the magnitude of the portion explained by occupation is in line with that in other studies. Recent work from the United States found that occupational complexity of the longest held job explained betwen $11 \%$ and $22 \%$ of education's association with cognitive function, in a sample of adults aged over 44 years (Fujishiro et al., 2017). This study was wholly based on a selection-on-observables identification strategy; the findings are less plausible as causal estimates.

Due to their large sample size, Fujishiro et al. (2017) were able to examine mediation 
effects among gender and race subgroups, as well across different margins of education. Occupational complexity explained differing amounts of the effect of education on cognition across subgroups-especially at the highest levels of education. A potential explanation suggested is differential skill mismatches in the labour market: if workers do not find roles which match their education level, they may not obtain the full cognitive returns to their education. Altenatively, for the same occupation, there may be heterogeneous cognitive returns across groups. Although the sample size in the present paper is too small to investigate more granular subgroups, exploring differences in the role of occupation by subgroup—gender, age, ethnicity and region—may represent a useful avenue for future work.

If occupation does represent a causal pathway between education and cognitive outcomes, this suggests a second policy lever after full-time education has been completedsupporting young people into employment, providing training to assist with continued work and engagement in later life, and matching employees with work commensurate with their skill set. Although the effects of occupation may themselves operate through subsequent mediating variables that may come with higher status occupations-autonomy and control over job tasks, positive peer group effects, a healthy and safe work environmentoccupational mismatch and employment conditions may still represent a "catch-all" indicator for policy intervention. The positive contribution of technical skill usage provides support that effect is not entirely due occupational social status.

The findings also highlight the role of the type of work in sustaining mental performance. Continuing to work into later life in a role which is not engaging, or is physically hazardous, would not be expected to provide continuing benefits. In this case, work-like activities which provide mental engagement, such as volunteering or other non-market activity, may be effective in maintaining long-term cognitive health. Empirical evidence for this hypothesis is provided in Andel et al. (2015), who assess the role of mid-life occupational complexity and leisure activity on late-life cognition, and suggest that such non-market activity can compensate for a lack challenging paid work, and vice versa. 


\section{Concluding Remarks}

Continued increases of the minimum school leaving age aim to improve the educational, economic and social prospects of those individuals who would otherwise choose to drop out early. Successive changes of this kind have increased average years of education over the the last century. Given these policies are not without cost, the size of social and private returns remains an important question. This paper used a change in compulsory schooling laws enacted in 1972 in England and Wales to study the effects of schooling on later-life cognitive performance. The findings show that an additional year of high school confers a protective effect on memory, ranging from one- to two-thirds of a standard deviation, depending on the sample and model specification employed. Little evidence was detected for effects on numeric ability or verbal fluency.

These results are in line with previous studies which have generally found a large impact of schooling on working memory, across a range of time periods, countries and estimation strategies, among those at the lower end of the schooling distribution (Glymour et al., 2008; Banks and Mazzonna, 2012; Schneeweis et al., 2014; Mazzonna, 2014). Compared with the estimates presented in the most similar study_Banks and Mazzonna (2012), who exploited the 1947 raising of the school leaving age in England and Walesthe effects of schooling on memory are similar in magnitude. The treatment effects are informed only by those individuals who changed their behaviours due to the schooling reform, those who otherwise would have chosen to leave school at age 15 years, rather than the average student. The causal estimates of schooling on cognitive outcomes for this subgroup exceed the OLS estimates-doubling in magnitude in some cases. This finding is consistent with the hypothesis that these "marginal" students, forced to stay on, may be those with most to gain from basic education.

Little is known about the transmission mechanisms of these treatment effects. This study conducted a formal analyses of the mechanisms, focussing on the role of occupation type. The effect size of the contribution of occupation type is large, explaining up to onefifth of the total effect-in line with other studies. However, the figures are imprecisely 
estimated, and occupation choice remains an avenue for future study. 


\section{Bibliography}

Sara Ahmadi-Abhari, Maria Guzman-Castillo, Piotr Bandosz, Martin J. Shipley, Graciela Muniz-Terrera, Archana Singh-Manoux, Mika Kivimäki, Andrew Steptoe, Simon Capewell, Martin O’Flaherty, and Eric J. Brunner. Temporal trend in dementia incidence since 2002 and projections for prevalence in England and Wales to 2040: modelling study. BMJ, 358:1-11, 2017. ISSN 0959-8138. doi: 10.1136/bmj.j2856.

Ross Andel, Merril Silverstein, and Ingemar Kareholt. The role of midlife occupational complexity and leisure activity in late-life cognition. Journals of Gerontology - Series B Psychological Sciences and Social Sciences, 70(2):314-321, 2015. ISSN 10795014. doi: 10.1093/geronb/gbu110.

Joshua D. Angrist and Guido W. Imbens. Two-stage least squares estimation of average causal effects in models with variable treatment intensity. Journal of the American Statistical Association, 90(430):431-442, 1995. ISSN 01621459. doi: 10.2307/2291054.

James Banks and Fabrizio Mazzonna. The effect of education on old age cognitive abilities: evidence from a Regression Discontinuity Design. The Economic Journal, 122 (560):418-448, may 2012. ISSN 00130133. doi: 10.1111/j.1468-0297.2012.02499.x.

Otávio C Bartalotti and Quentin O Brummet. Regression Discontinuity Designs with clustered data. Advances in Econometrics, 38, 2016.

John R. Beard, Alana Officer, and Andrew Cassels. World report on ageing and health. Technical report, World Health Organization, Geneva, 2015.

Patricia A. Boyle, Lei Yu, Robert S. Wilson, Keith Gamble, Aron S. Buchman, and David A. Bennett. Poor decision making is a consequence of cognitive decline among older persons without alzheimer's disease or mild cognitive impairment. PLOS ONE, 7 (8):5-9, 2012. ISSN 19326203. doi: 10.1371/journal.pone.0043647. 
Kasey S. Buckles and Daniel M. Hungerman. Season of birth and later outcomes: Old questions, new answers. Review of Economics and Statistics, 95(3):711-724, 2013. ISSN 0034-6535.

Sebastian Calonico, Matias D. Cattaneo, and Max H Farrell. rdrobust: Software for Regression Discontinuity Designs. (ii):1-29, 2016.

Anne Case and Angus S Deaton. Broken down by work and sex: How our health declines. In Analyses in the Economics of Aging, pages 185-212. University of Chicago Press, 2005.

Anne Case and Christina Paxson. Early life health and cognitive function in old age. The American Economic Review, 2009.

Geneviève Chêne, Carole Dufouil, and Sudha Seshadri. Incidence of dementia over three decades in the Framingham Heart Study. New England Journal of Medicine,, 374(6): 523-532, 2016. ISSN 0028-4793. doi: 10.1056/NEJMoa1504327.

Arnaud Chevalier, Colm Harmon, Ian Walker, and Yu Zhu. Does education raise productivity, or just reflect It? The Economic Journal, 114(499):F499-F517, nov 2004. ISSN 00130133. doi: $10.2307 / 3590169$.

Damon Clark and Heather Royer. The effect of education on adult mortality and health: Evidence from Britain. American Economic Review, 103(6):2087-2120, 2013. ISSN 00028282. doi: 10.1257/aer.103.6.2087.

Rosa M Crum, James C Anthony, Susan S Bassett, and Marshal F Folstein. Populationbased norms for the Mini-Mental State Examination by age and educational level. Journal of the American Medical Association, 269(18):2386-2391, 1993. ISSN 0098-7484.

Ian J. Deary, Janie Corley, Alan J. Gow, Sarah E. Harris, Lorna M. Houlihan, Riccardo E. Marioni, Lars Penke, Snorri B. Rafnsson, and John M. Starr. Age-associated cognitive 
decline. British Medical Bulletin, 92(1):135-152, 2009. ISSN 00071420. doi: 10.1093/ bmb/ldp033.

Department for Work and Pensions. 2010 to 2015 government policy: older people. Technical report, 2013. URL https://www.gov.uk/government/ publications/2010-to-2015-government-policy-older-people.

Andy Dickerson, Rob Wilson, Genna Kik, and Debra Dhillon. Developing Occupational Skills Profiles for the UK: A Feasibility Study. Technical Report February, UK Comission for Employment and Skills, 2012. URL http://www.ukces.org.uk/publications/ er44-developing-occupational-skills-profiles-for-the-uk \{\%\} 5Cnhttp: //www.ukces.org.uk/assets/ukces/docs/publications/ evidence-report-44-developing-occupational-skills-profiles-for-the-uk pdf.

Matt Dickson and Sarah Smith. What determines the return to education: An extra year or a hurdle cleared? Economics of Education Review, 30(6):1167-1176, 2011. ISSN 02727757. doi: 10.1016/j.econedurev.2011.05.004.

Matt Dickson, Paul Gregg, and Harriet Robinson. Early, late or never? When does parental education impact child outcomes? The Economic Journal, 126(596):F184-F231, oct 2016. ISSN 00130133. doi: 10.1111/ecoj.12356.

Gwenith G. Fisher, Alicia Stachowski, Frank J. Infurna, Jessica D. Faul, James Grosch, and Lois E. Tetrick. Mental work demands, retirement, and longitudinal trajectories of cognitive functioning. Journal of Occupational Health Psychology, 19(2):231-242, 2014. ISSN 1939-1307. doi: 10.1037/a0035724. URL http://doi.apa.org/ getdoi.cfm?doi=10.1037/a0035724.

James R. Flynn. Massive IQ gains in 14 nations: What IQ tests really measure. Psycholog- 
ical Bulletin, 101(2):171-191, 1987. ISSN 1939-1455(Electronic);0033-2909(Print). doi: 10.1037/0033-2909.101.2.171.

Kaori Fujishiro, Leslie A MacDonald, Michael Crowe, Leslie A McClure, Virginia J Howard, and Virginia G Wadley. The Role of Occupation in Explaining Cognitive Functioning in Later Life: Education and Occupational Complexity in a U.S. National Sample of Black and White Men and Women. The Journals of Gerontology: Series B, 00(00):1-11, 2017. ISSN 1079-5014. doi: 10.1093/geronb/gbx112.

M. Maria Glymour, Ichiro Kawachi, Christopher S. Jencks, and Lisa F. Berkman. Does childhood schooling affect old age memory or mental status? Using state schooling laws as natural experiments. Journal of Epidemiology and Community Health, 62(6): 532-537, 2008. doi: 10.1136/jech.2006.059469.

Michael Grossman. On the Concept of Health Capital and the Demand for Health. Journal of Political Economy, 1972. ISSN 00223808.

Jinyong Hahn, Petra E. Todd, and Wilbert van der Klaauw. Identification and estimation of treatment effects with a Regression-Discontinuity Design. Econometrica, 1(69):201209, 2001.

Colm Harmon and Ian Walker. Estimates of the economic return to schooling for the United Kingdom. The American Economic Review, 85(5):1278-1286, 1995.

James J. Heckman. The technology and neuroscience of capacity formation. PNAS, I(1): $1-8,2006$.

James J. Heckman, Jora Stixrud, and Sergio Urzua. The effects of cognitive and noncognitive abilities on labor market outcomes and social behavior. Journal of Labor Economics, 2006. ISSN 0734306X.

Joanna Hsu and Robert Willis. Dementia Risk and Financial Decision Making by Older 
Households: The Impact of Information. Journal of Human Capital, 45:1-40, 2013. doi: 10.2139/ssrn.2339225.Dementia.

Wei Huang and Yi Zhou. Effects of education on cognition at older ages: Evidence from China's Great Famine. Social Science and Medicine, 98:54-62, 2013. ISSN 02779536. doi: 10.1016/j.socscimed.2013.08.021.

Martin Huber, Michael Lechner, and Giovanni Mellace. The finite sample performance of estimators for mediation analysis under sequential conditional independence. Journal of Business \& Economic Statistics, 0015(July 2015):0-0, 2015. ISSN 0735-0015. doi: 10.1080/07350015.2015.1017644.

Kosuke Imai, Luke Keele, Dustin Tingley, and Teppei Yamamoto. Unpacking the black box of causality: Learning about causal mechanisms from experimental and observational studies. American Political Science Review, 105(04):765-789, 2011. ISSN 0003-0554. doi: $10.1017 / \mathrm{S} 0003055411000414$.

Guido W. Imbens and Thomas Lemieux. Regression discontinuity designs: A guide to practice. Journal of Econometrics, 142(2):615-635, 2008.

Institute for Social and Economic Research and NatCen Social Research. Understanding Society: Waves 1-5, 2009-2014: Special Licence Access. 6th Edition. SN: 6931, 2015.

Luke Keele, Dustin Tingley, and Teppei Yamamoto. Identifying mechanisms behind policy interventions via causal mediation analysis. Journal of Policy Analysis and Management, 34(4):937-963, 2015. ISSN 15206688. doi: 10.1002/pam.21853.

Jee Wook Kim, Dong Young Lee, Eun Hyun Seo, Bo Kyung Sohn, Young Min Choe, Shin Gyeom Kim, Shin Young Park, I L Han Choo, Jong Chul Youn, Jin Hyeong Jhoo, Ki Woong Kim, and Jong Inn Woo. Improvement of screening accuracy of Mini-Mental State Examination for mild cognitive impairment and Non-Alzheimer's Disease Dementia by supplementation of verbal fluency performance. Psychiatry Investigation, 11(1): 44-51, jan 2014. ISSN 1738-3684. doi: 10.4306/pi.2014.11.1.44. 
David S. Lee and David Card. Regression discontinuity inference with specification error. Journal of Econometrics, 142(2):655-674, feb 2008. ISSN 0304-4076. doi: http://dx. doi.org/10.1016/j.jeconom.2007.05.003.

Gill Livingston, Andrew Sommerlad, Vasiliki Orgeta, Sergi G. Costafreda, Jonathan Huntley, David Ames, Clive Ballard, Sube Banerjee, Alistair Burns, Jiska CohenMansfield, Claudia Cooper, Nick Fox, Laura N. Gitlin, Robert Howard, Helen C. Kales, Eric B. Larson, Karen Ritchie, Kenneth Rockwood, Elizabeth L. Sampson, Quincy Samus, Lon S. Schneider, Geir Selbæk, Linda Teri, and Naaheed Mukadam. Dementia prevention, intervention, and care. The Lancet, 2017. ISSN 0140-6736. doi: http://dx.doi.org/10.1016/S0140-6736(17)31363-6.

Lance Lochner. Nonproduction Benefits of Education: Crime, Health, and Good Citizenship. In Handbook of the Economics of Education, page 183. Elsevier, 2011.

Bhashkar Mazumder. The effects of education on health and mortality. Nordic Economic Policy Review, 2012. ISSN 19044526.

Fabrizio Mazzonna. The long lasting effects of education on old age health: evidence of gender differences. Social Science \& Medicine, 101:129-38, jan 2014. ISSN 18735347. doi: 10.1016/j.socscimed.2013.10.042.

Fabrizio Mazzonna and Franco Peracchi. Ageing, cognitive abilities and retirement. European Economic Review, 56(4):691-710, 2012.

Fabrizio Mazzonna and Franco Peracchi. Unhealthy Retirement? Journal of Human Resources, 2017.

Stephanie McFall. Understanding Society The UK Household Longitudinal Study Waves 1-3, User Manual. Colchester: University of Essex, 2013a.

Stephanie McFall. Understanding Society the UK Household longitudinal study: Cognitive ability Measures. Understanding Society, 2013b. 
Jaana-Marja Muurinen. Demand for health: A Generalised Grossman model. Journal of Health Economics, 1:5-28, 1982.

OECD. Live Longer, Work Longer, 2006. URL http://www.oecd.org/ employment/livelongerworklonger.htm.

Philip Oreopoulos. Estimating average and local average treatment effects of education when compulsory schooling laws really matter. American Economic Review, 96(1): 152-175, 2006. ISSN 0002-8282. doi: 10.1257/000282806776157641.

Philip Oreopoulos and Kjell G. Salvanes. Priceless: The nonpecuniary benefits of schooling. Journal of Economic Perspectives, 25(1):159-184, feb 2011. ISSN 0895-3309. doi: $10.1257 /$ jep.25.1.159.

Soojin Park. Abstract: Identifying Average Causal Mediation Effects with Multiple Mediators in the Presence of Treatment Noncompliance. Multivariate Behavioral Research, 50(1):141, jan 2015. ISSN 0027-3171. doi: 10.1080/00273171.2014.989008.

Brenda L. Plassman, Kathleen. A. Welsh, M. Helms, Jason Brandt, William F. Page, and John C. S. Breitner. Intelligence and education as predictors of cognitive state in late life: A 50-year follow-up. Neurology, 45(8):1446-1450, 1995. ISSN 0028-3878.

Martin Prince, Martin Knapp, Maëlenn Guerchet, and Paul McCrone. Dementia UK: Update. Technical Report 1, Alzheimer's Society, London, 2014.

Susann Rohwedder and Robert J Willis. Mental retirement. Journal of Economic Perspectives, 24(October 2009):1-19, 2010. doi: 10.1257/jep.24.1.119.Mental.

M. Roth, E. Tym, C. Q. Mountjoy, Felicia A. Huppert, H. Hendrie, S. Verma, and R. Goddard. CAMDEX. A standardised instrument for the diagnosis of mental disorder in the elderly with special reference to the early detection of dementia. The British Journal of Psychiatry, 149(6):698-709, dec 1986. ISSN 0007-1250. doi: 10.1192/bjp.149.6.698. 
Nicole Schneeweis, Vegard Skirbekk, and Rudolf Winter-Ebmer. Does education improve cognitive performance four decades after school completion? Demography, 51(2):619_ 643, apr 2014. ISSN 0070-3370 (Print). doi: 10.1007/s13524-014-0281-1.

Vegard Skirbekk, Marcin Stonawski, Eric Bonsang, and Ursula M. Staudinger. The Flynn effect and population aging. Intelligence, 41(3):169-177, 2013. ISSN 01602896. doi: 10.1016/j.intell.2013.02.001.

Yaakov Stern. What is cognitive reserve? Theory and research application of the reserve concept. Journal of the International Neuropsychological Society, 8(03):448-460, 2002. ISSN 1469-7661. doi: 10.1017/S1355617702813248.

Elliot M. Tucker-Drob. Neurocognitive Functions and Everyday Functions Change Together in Old Age. Neuropsychology, 25(3):368-377, 2011. ISSN 09652140. doi: 10.1016/j.humov.2008.02.015.Changes.

Tom Woodin, Gary McCulloch, and Steven Cowan. Raising the participation age in historical perspective: policy learning from the past? British Educational Research Journal, (November):1-19, 2012. ISSN 0141-1926. doi: 10.1080/01411926.2012.668871.

Christina Wraw, Ian J. Deary, Catharine R. Gale, and Geoff Der. Intelligence in youth and health at age 50. Intelligence, 53:23-32, 2015. ISSN 01602896. doi: 10.1016/j.intell. 2015.08.001.

Qiong Wu, Eric J Tchetgen Tchetgen, Theresa L. Osypuk, Kellee White, Mahasin Mujahid, and M. Maria Glymour. Combining direct and proxy assessments to reduce attrition bias in a longitudinal study. Alzheimer Disease and Associated Disorders, 27(3):207, 2013.

Teppei Yamamoto. Identification and estimation of causal mediation effects with treatment noncompliance. 2014. 
Figure 1: The evolution of cognitive outcomes by age

(a) Word Recall

1

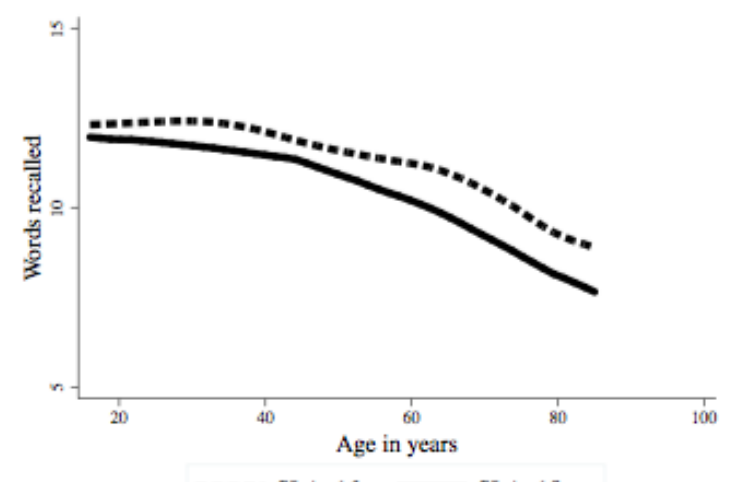

- $\mathrm{NLA}=16 \quad \mathrm{SLA}=15$

(c) Serial Subtraction

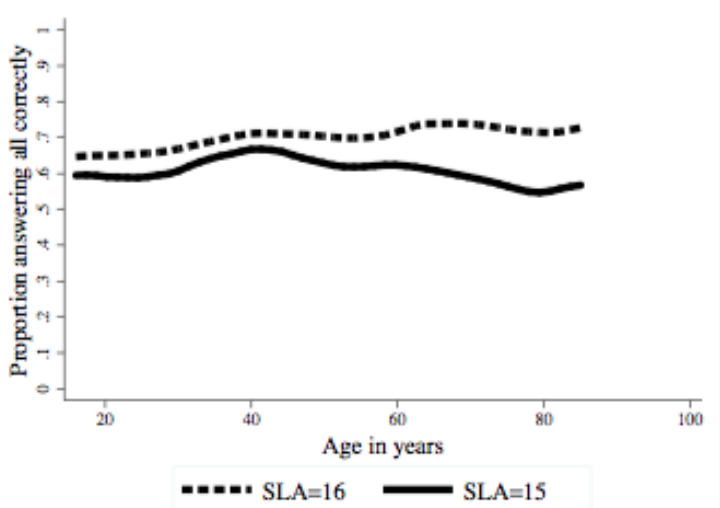

(b) Verbal Fluency

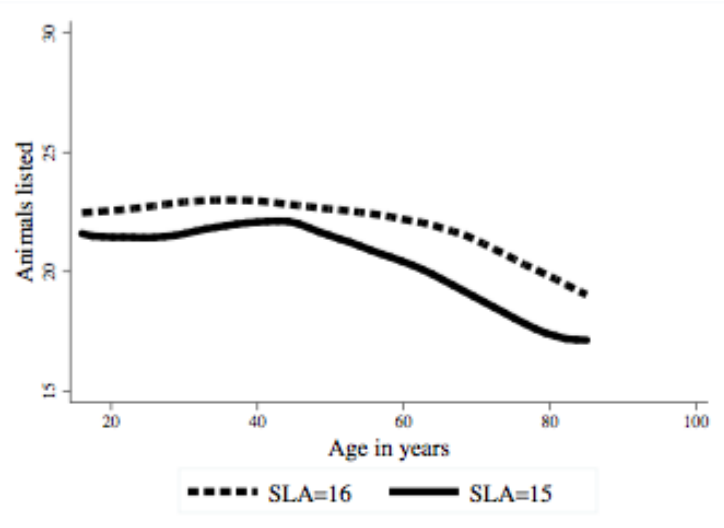

(d) Numeric Ability

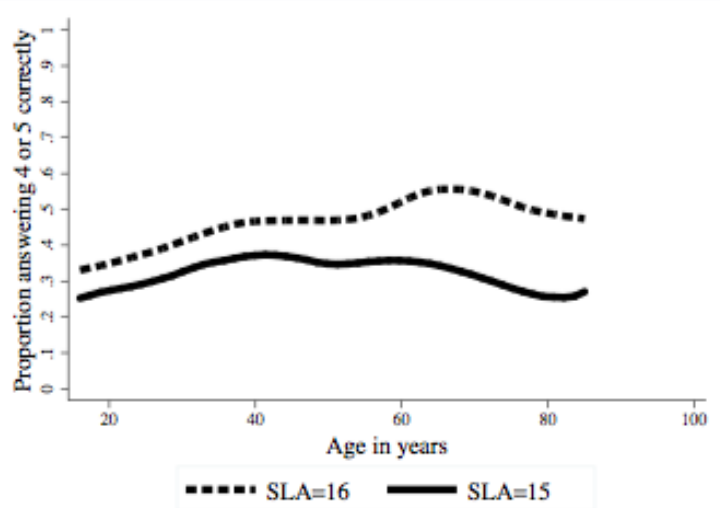

Notes: Mean cognitive outcomes (Word Recall, Verbal Fluency, Serial Subtraction and Numeric Ability) by age-at-interview and school leaving age (SLA), among those who left school at either 15 years or 16 years of age. 
Figure 2: Years of Schooling by month-year of birth

(a) Full sample

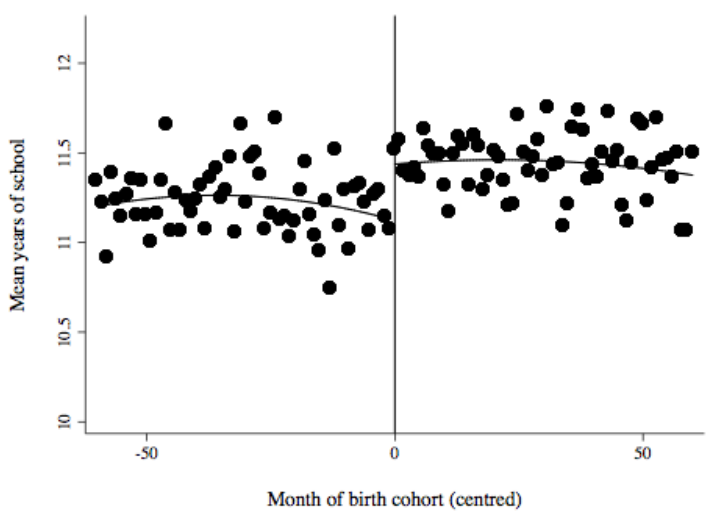

(b) Restricted to those who left school before age 17 years

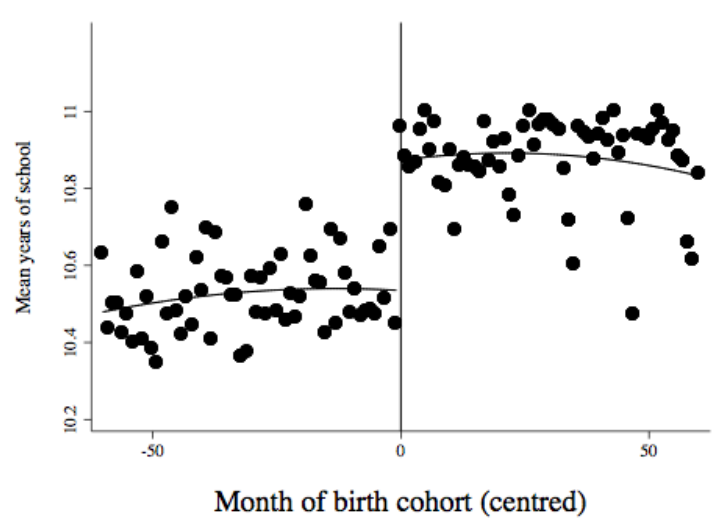

Notes: Sample means of years of school by month-of-birth cohort. 
Figure 3: Cognitive outcomes by birth cohort

(a) Word Recall

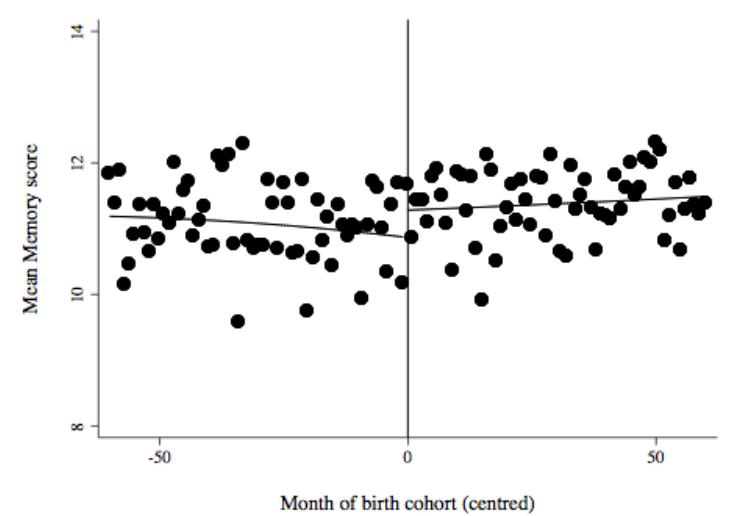

(c) Serial Subtraction

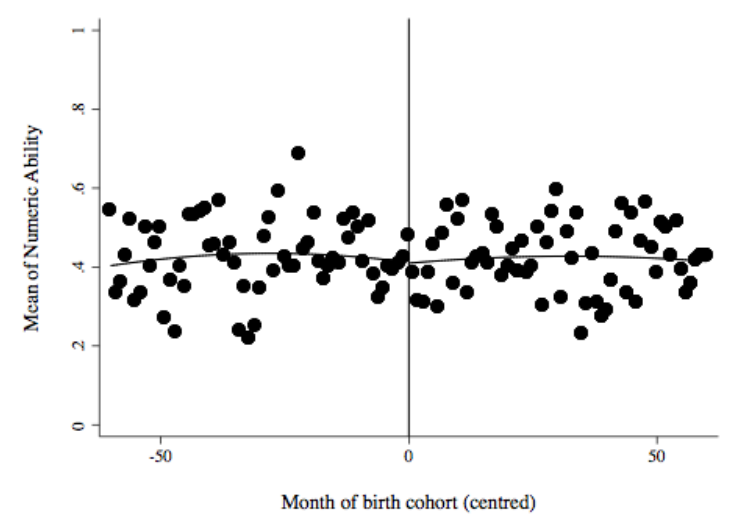

(b) Verbal Fluency

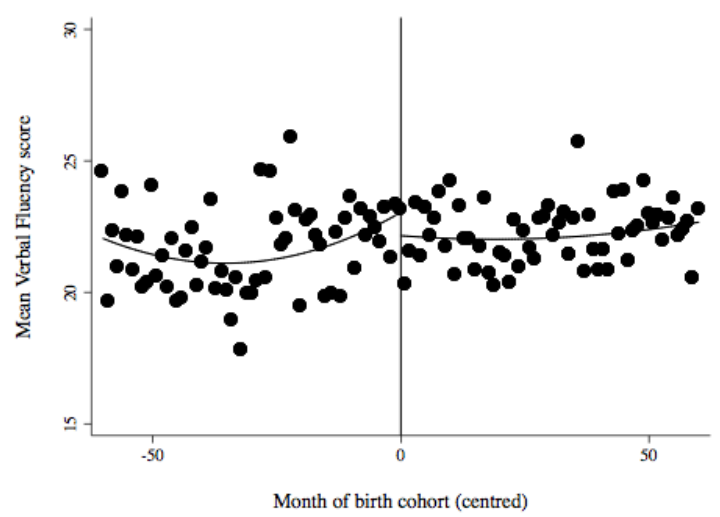

(d) Numeric Ability

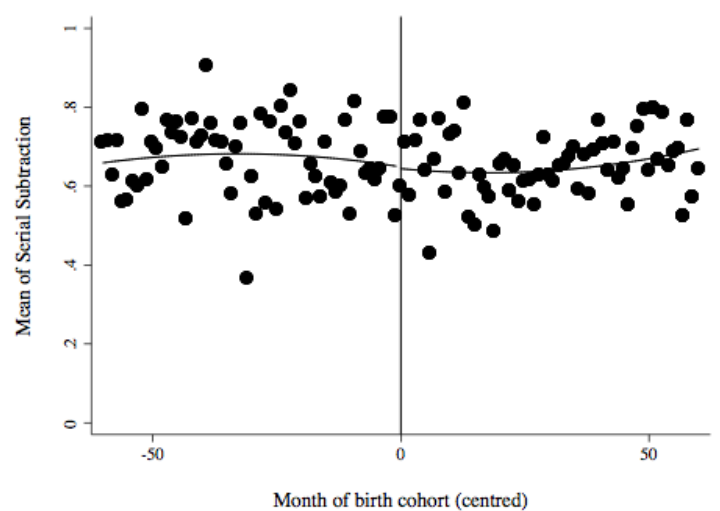

Notes: Sample means of Word Recall, Verbal Fluency, Serial Subtraction and Numeric Ability by monthof-birth cohort, overlaid with a quadratic fit. 
Figure 4: Sensitivity analyses

(a) Word Recall

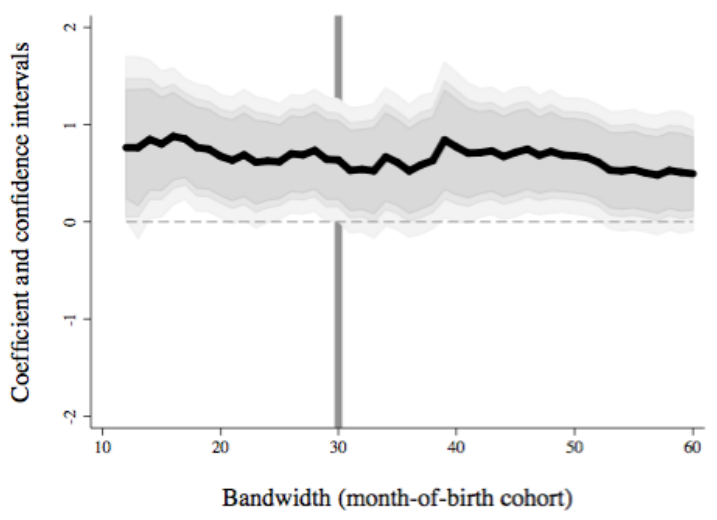

(c) Numeric ability

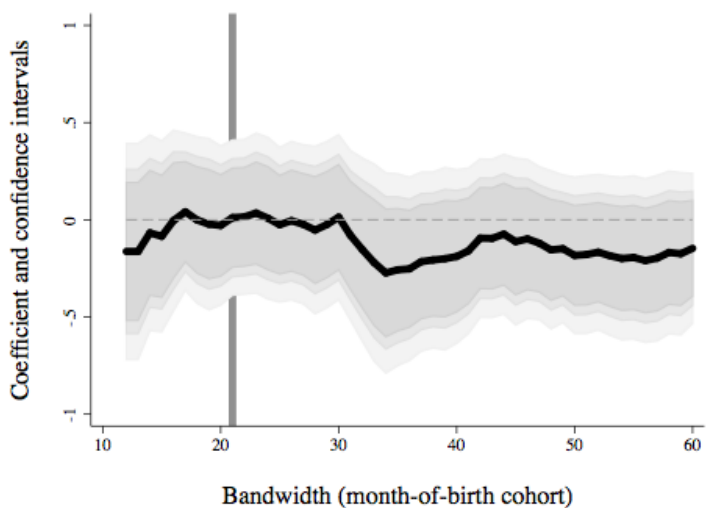

(b) Verbal fluency

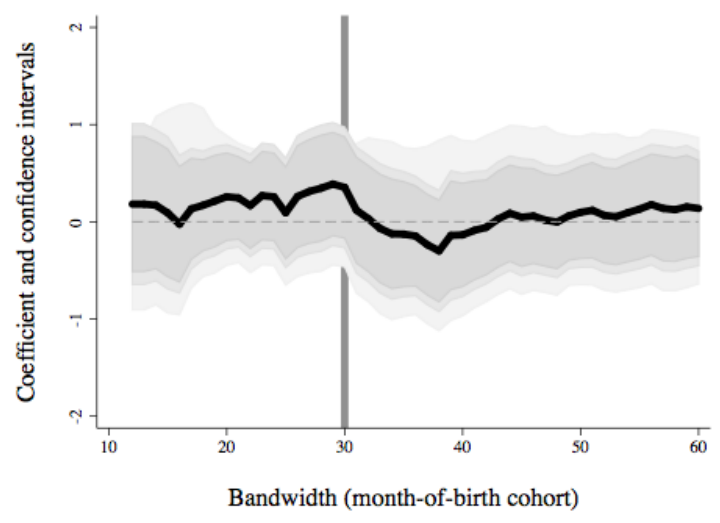

(d) Serial subtraction

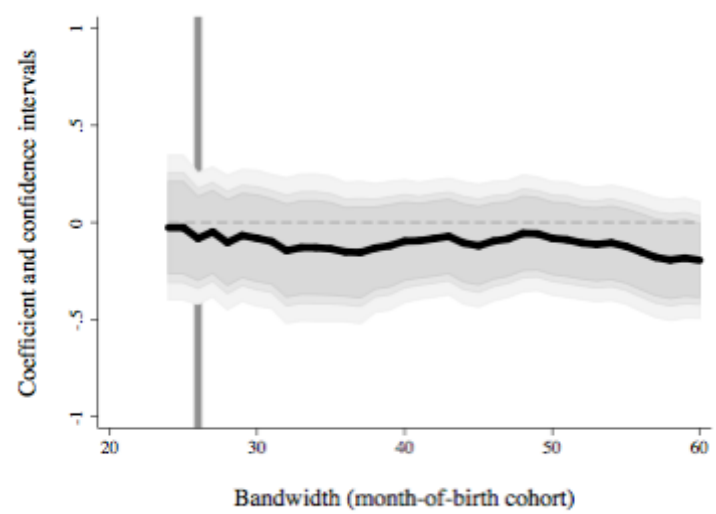

Notes: The bold black line plots coefficients from a fuzzy Regression Discontinuity Design assessing the effect of years of school on each cognitive outcome (Word Recall, Verbal Fluency, Numeric Ability, Serial Subtraction) across a range of bandwidth choices (22 month-year of birth cohorts to 60 month-year of birth cohorts). The grey areas depict 90\%, 95\% and 99\% confidence intervals around the treatment effect. The vertical line indicates the optimally chosen bandwidth. 
Table 1: Age left school (SLA), Before and After Reform

\begin{tabular}{|c|c|c|c|c|c|c|}
\hline \multirow{4}{*}{ SLA } & \multicolumn{3}{|c|}{ Men } & \multicolumn{3}{|c|}{ Women } \\
\hline & \multicolumn{2}{|c|}{ Treatment status } & \multirow{3}{*}{$\begin{array}{r}\text { Total } \\
\%\end{array}$} & \multicolumn{2}{|c|}{ Treatment status } & \multirow{3}{*}{ Total } \\
\hline & Non-treated & Treated & & Non-treated & Treated & \\
\hline & $\%$ & $\%$ & & & & \\
\hline 15 & 37.8 & 7.9 & 21.7 & 37.7 & 9.2 & 22.0 \\
\hline 16 & 30.1 & 60.3 & 46.4 & 33.1 & 60.0 & 47.9 \\
\hline 17 & 9.9 & 10.4 & 10.2 & 9.5 & 9.9 & 9.7 \\
\hline 18 & 19.9 & 19.7 & 19.8 & 18.9 & 19.8 & 19.4 \\
\hline 19 & 2.3 & 1.6 & 1.9 & 0.9 & 1.1 & 1.0 \\
\hline Total & 100.0 & 100.0 & 100.0 & 100.0 & 100.0 & 100.0 \\
\hline
\end{tabular}

Notes: Survey-weighted column percentages summarising age left secondary school (SLA), for men and women. The column Non-treated is restricted to respondents unexposed to the new the school leaving age, born before 01, September, 1957. The column Treated is restricted to respondents exposed to the new the school leaving age, born on or after 01, September, 1957. The sample is restricted to respondents born within five years of the treatment cut-off. 
Table 2: Summary statistics for demographic and cognitive variables

\begin{tabular}{|c|c|c|c|c|c|}
\hline \multirow[t]{2}{*}{ Variable } & Mean & SD & Min & Max & $\mathrm{N}$ \\
\hline & \multicolumn{5}{|c|}{ (a) Pooled sample } \\
\hline Female & 0.52 & 0.50 & 0.00 & 1.00 & 4,915 \\
\hline Age & 53.54 & 2.94 & 48.00 & 60.00 & 4,915 \\
\hline Years of school & 11.33 & 1.04 & 10.00 & 14.00 & 4,833 \\
\hline Word recall & 11.60 & 3.23 & 0.00 & 20.00 & 4,797 \\
\hline Verbal Fluency & 22.93 & 6.80 & 0.00 & 71.00 & 4,877 \\
\hline Numeracy & 0.53 & 0.50 & 0.00 & 1.00 & 4,864 \\
\hline \multirow[t]{2}{*}{ Serial Subtraction } & 0.71 & 0.45 & 0.00 & 1.00 & 4,779 \\
\hline & \multicolumn{5}{|c|}{ (b) Women } \\
\hline Age & 53.49 & 2.95 & 48.00 & 60.00 & 2,747 \\
\hline Years of school & 11.30 & 1.02 & 10.00 & 14.00 & 2,709 \\
\hline Word recall & 11.93 & 3.25 & 0.00 & 20.00 & 2,679 \\
\hline Verbal Fluency & 22.84 & 6.75 & 0.00 & 71.00 & 2,726 \\
\hline Numeracy & 0.42 & 0.49 & 0.00 & 1.00 & 2,716 \\
\hline \multirow[t]{2}{*}{ Serial Subtraction } & 0.66 & 0.47 & 0.00 & 1.00 & 2,653 \\
\hline & \multicolumn{5}{|c|}{ (c) Men } \\
\hline Age & 53.60 & 2.93 & 48.00 & 60.00 & 2,168 \\
\hline Years of school & 11.37 & 1.06 & 10.00 & 14.00 & 2,124 \\
\hline Word recall & 11.25 & 3.17 & 0.00 & 20.00 & 2,118 \\
\hline Verbal Fluency & 23.02 & 6.86 & 0.00 & 51.00 & 2,151 \\
\hline Numeracy & 0.64 & 0.48 & 0.00 & 1.00 & 2,148 \\
\hline Serial Subtraction & 0.77 & 0.42 & 0.00 & 1.00 & 2,126 \\
\hline
\end{tabular}

Notes: Weighted summary statistics for analysis variables for men, women and the pooled sample. Restricted to respondents born five years before or after the 01, September, 1957. 
Table 3: OLS and RD estimates of the effect of schooling on cognitive outcomes (among respondents who left school before age 17 years)

\begin{tabular}{|c|c|c|c|c|c|c|c|c|}
\hline & \multicolumn{8}{|c|}{ Outcome } \\
\hline & \multicolumn{2}{|c|}{ Word recall } & \multicolumn{2}{|c|}{ Verbal Fluency } & \multicolumn{2}{|c|}{ Numeric Ability } & \multicolumn{2}{|c|}{ Subtraction } \\
\hline & OLS & $\mathrm{RD}$ & OLS & $\mathrm{RD}$ & OLS & $\mathrm{RD}$ & OLS & $\mathrm{RD}$ \\
\hline & \multicolumn{8}{|c|}{ (a) $R D$ treatment effect } \\
\hline Years & 0.15 & 0.53 & 0.18 & 0.15 & 0.16 & 0.17 & 0.10 & -0.14 \\
\hline \multirow[t]{2}{*}{ Std. Err } & 0.06 & 0.28 & 0.06 & 0.38 & 0.04 & 0.12 & 0.04 & 0.17 \\
\hline & \multicolumn{8}{|c|}{ (b) First-stage statistics } \\
\hline First-stage $\hat{\beta}$ & & 0.33 & & 0.34 & & 0.44 & & 0.38 \\
\hline \multirow[t]{2}{*}{$F$-statistic } & & 35.35 & & 36.08 & & 41.21 & & 35.86 \\
\hline & \multicolumn{8}{|c|}{ (c) Sample size } \\
\hline Bandwidth & 30 & 30 & 30 & 30 & 21 & 21 & 26 & 26 \\
\hline$N$ & 939 & 939 & 950 & 950 & 671 & 671 & 810 & 810 \\
\hline
\end{tabular}

Notes: Panel(a) reports results from OLS and FRD regressions assessing the effect of an additional year of schooling on each cognitive outcome. The sample is restricted to respondents who left school before age 17 years, and reported complete data on their occupation history. Each model adjusts for the following covariates: a linear trend in month-year of birth cohort (interacted with the reform dummy), indicators for gender, interview month, interview year and a quadratic term in age. The standard errors are clustered by month-year of birth cohort. Survey weights adjusting for unit non-response and sample design were used in all specifications. Panel $(b)$ presents the first-stage statistics. First-stage $\hat{\beta}$ is the coefficient on the reform dummy in the first stage regression. $F$-statistic is the robust F-statistic for the first-stage. Panel $(c)$ shows the sample size. Bandwidth refers to the number of month-year of birth cohorts included in the estimation sample on each side of the treatment cut-off, selected using a data-driven procedure. $N$ is the sample size used in each regression. 
Table 4: Summary statistics for occupation variables

\begin{tabular}{lrr}
\hline Variable & Column \% / Mean & $\mathrm{N}$ \\
\cline { 2 - 3 } NS-SEC (first job) & & \\
Semi-routine; routine; LT unemployed & 23.1 & 1,584 \\
Lower supervisory and technical & 34.0 & 2,334 \\
Small employers and own account & 5.6 & 387 \\
Intermediate occupations & 25.3 & 1,738 \\
Lower managerial; Higher managerial and professional & 12.0 & 823 \\
Total & 100.0 & 6,867
\end{tabular}

\section{NS-SEC (current job)}

Semi-routine; routine; LT unemployed

Lower supervisory and technical

Small employers and own account

Intermediate occupations

12.6

Lower managerial; Higher managerial and professional

40.6

Total

100.0

\section{Skills}

Technical skills (in first job)

Notes: Weighted column percentages for occupation variables. Restricted to respondents born five years before or after the 01, September, 1957 who left school before age 17 years. 
Table 5: Causal effects of one additional year of schooling on intermediate variables

\begin{tabular}{|c|c|c|}
\hline \multirow[t]{2}{*}{ Outcomes } & $\begin{array}{r}\text { Average marginal } \\
\text { effects }\end{array}$ & Standard error \\
\hline & \multicolumn{2}{|c|}{ Panel (a) } \\
\hline \multicolumn{3}{|l|}{$N S-S E C$ (first job) } \\
\hline Routine; semi-routine & -0.11 & 0.02 \\
\hline Lower supervisory and technical & -0.01 & 0.00 \\
\hline Small employers and own account & 0.01 & 0.00 \\
\hline Intermediate occupations & 0.07 & 0.01 \\
\hline Managerial and professional & 0.04 & 0.00 \\
\hline \multicolumn{3}{|c|}{ Panel (b) } \\
\hline \multicolumn{3}{|l|}{$N S$-SEC (current job) } \\
\hline Routine; semi-routine & -0.16 & 0.01 \\
\hline Lower supervisory and technical & -0.01 & 0.00 \\
\hline Small employers and own account & 0.01 & 0.00 \\
\hline Intermediate occupations & 0.02 & 0.00 \\
\hline Managerial and professional & 0.14 & 0.01 \\
\hline \multicolumn{3}{|c|}{ Panel (c) } \\
\hline \multicolumn{3}{|l|}{ Technical skills } \\
\hline Cognitive skills & 1.72 & 0.80 \\
\hline \multicolumn{3}{|c|}{$\begin{array}{l}\text { Notes: This table reports results from three separate instrumental variable (IV) pro- } \\
\text { cedures, assessing the effect of an additional year of schooling on the intermediate } \\
\text { outcomes using the RoSLA as the IV. Panel( } a \text { ) shows results from an IV ordered pro- } \\
\text { bit model, with occupation type of first job as the outcome. Panel(b) shows results } \\
\text { from an IV ordered probit model, with occupation type of current job as the outcome. } \\
\text { These two specifications were estimated using Maximum Likelihood via the - cmp- } \\
\text { Stata package. The third specification, in Panel( }(\text { ) shows results from a } 2 \text { SLS regres- } \\
\text { sion with Technical Skill usage as the outcome. The covariates in each specification } \\
\text { are: a linear trend in month-year of birth cohort (interacted with the reform dummy), } \\
\text { indicators for gender, interview month, interview year, and a quadratic term in age. } \\
\text { The standard errors are clustered by month-year of birth cohort (the running variable). } \\
\text { Survey weights adjusting for unit non-response and sample design are used in all spec- } \\
\text { ifications. }\end{array}$} \\
\hline
\end{tabular}


Table 6: Causal mechanisms: LACME and LANDE

\begin{tabular}{|c|c|c|c|c|c|c|}
\hline & \multicolumn{2}{|c|}{ Occupation (first job) } & \multicolumn{2}{|c|}{ Occupation (current job) } & \multicolumn{2}{|c|}{ Technical skills } \\
\hline & Estimate & Std. Error & Estimate & Std. Error & Estimate & Std. Error \\
\hline LATE & 0.52 & $(0.35)$ & 0.53 & $(0.36)$ & 0.53 & $(0.36)$ \\
\hline \multicolumn{7}{|l|}{ LANDE } \\
\hline$\tilde{\zeta}(0)$ & 0.50 & $(0.72)$ & 0.47 & $(0.65)$ & 0.53 & $(0.73)$ \\
\hline$\tilde{\zeta}(1)$ & 0.52 & $(0.53)$ & 0.47 & $(0.40)$ & 0.43 & $(0.38)$ \\
\hline \multicolumn{7}{|l|}{ LACME } \\
\hline$\tilde{\delta}(0)$ & 0.00 & $(0.40)$ & 0.06 & $(0.54)$ & 0.00 & $(0.52)$ \\
\hline$\tilde{\delta}(1)$ & 0.02 & $(0.60)$ & 0.06 & $(0.24)$ & 0.10 & $(0.30)$ \\
\hline Bandwidth & 30 & 30 & 30 & 30 & 30 & 30 \\
\hline$N$ & 939 & 939 & 939 & 939 & 939 & 939 \\
\hline
\end{tabular}

Notes: This table shows estimates of the local average treatment effect (LATE) of one additional year of schooling on Word Recall, and decomposes this into components explained and unexplained by three alternative intermediate variable (Occupation type of first job, Occupation type of current job, Technical skills in first job). $\tilde{\zeta}(0)$ and $\tilde{\zeta}(1)(\tilde{\delta}(0)$ and $\tilde{\delta}(1))$ denote estimates of the LACME (LANDE) when the treatment is fixed to either $d=0$ or $d=1$, respectively. Each model adjusts for the following covariates: linear trend in month-year of birth cohort interacted with the reform dummy, indicators for gender, interview month, interview year, age. Bandwidth refers to the number of month-year of birth cohorts included in the estimation sample on each side of the treatment cut-off. 


\section{A Distributions of variables}

Figure 5 displays the distribution of raw data for the main cognitive outcome variables considered. Word recall and verbal fluency are continuous measures, and were subsequently standardised to have mean zero and standard deviation of 1 . The results are robust to excluding zero values for word recall and verbal fluency.

Figure 5: Histograms of variables
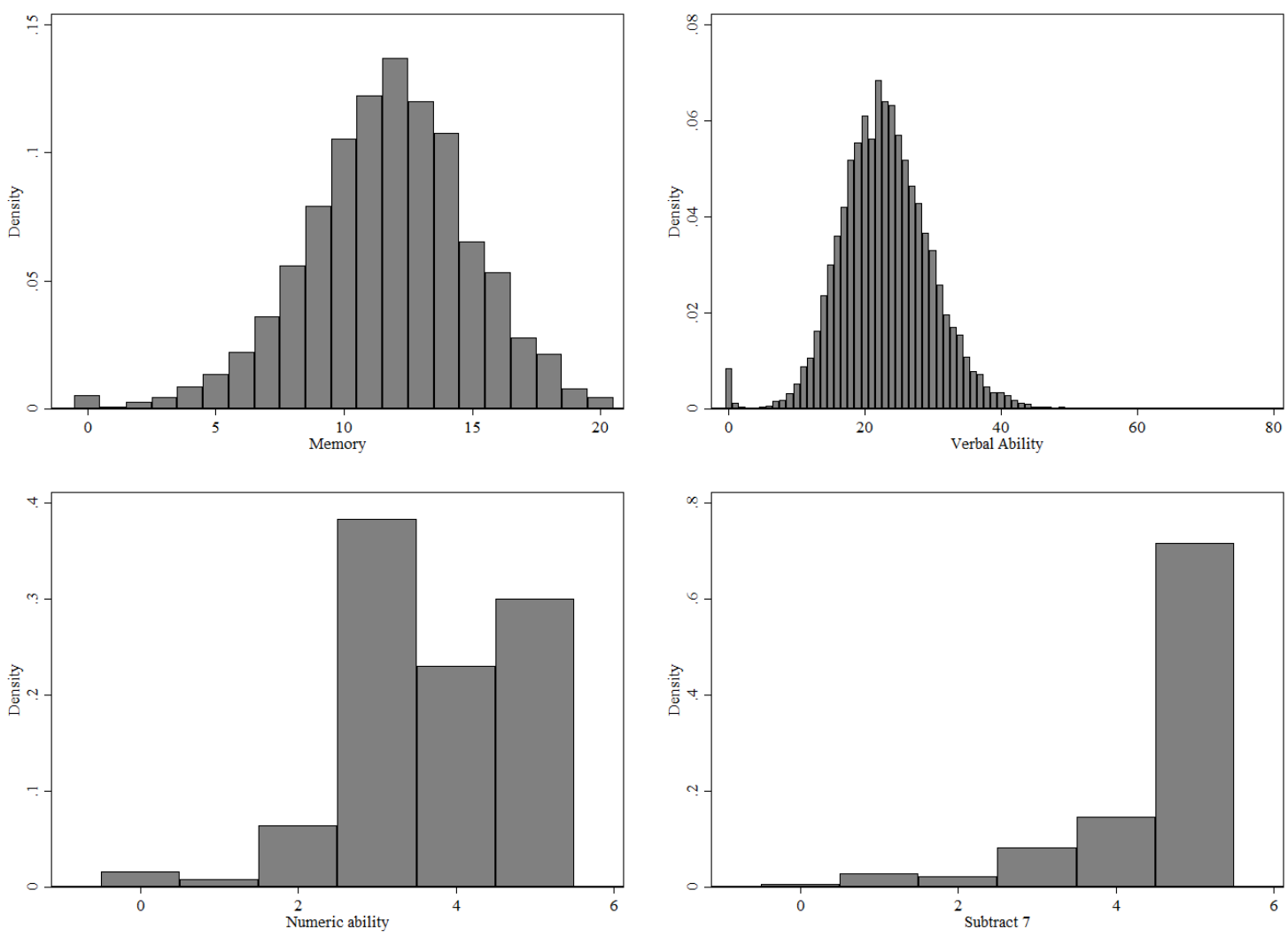


\section{B Sensitivity analyses}

Figure 6 assesses the sensitivity of the main results to changes in the bandwidth choice, now using a quadratic specification for the running variable. The treatment effect coefficient and confidence intervals $(90 \%, 95 \%, 99 \%)$ are plotted for models with different bandwidths, from 24 months to 121 months (units born within 2 years either side of the reform up to 10 years either side). As in the main text, this sample is restricted to respondents who left school before age 17 years.

Figure 6: Sensitivity analyses

(a) Memory: Quadratic

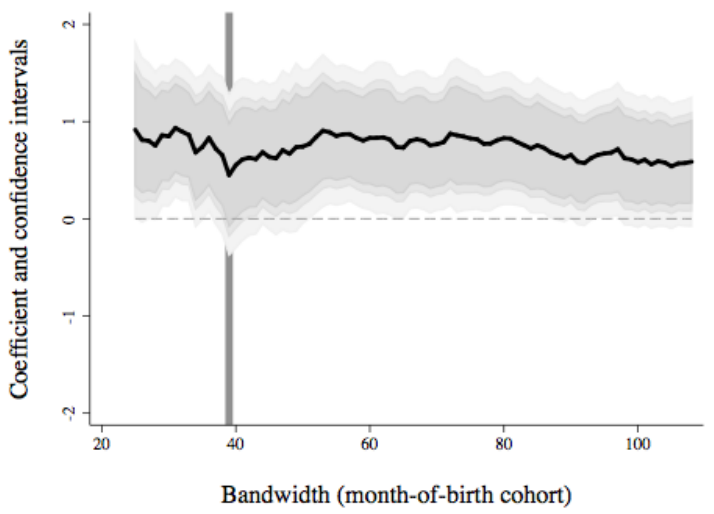

(c) Serial Subtraction: Quadratic

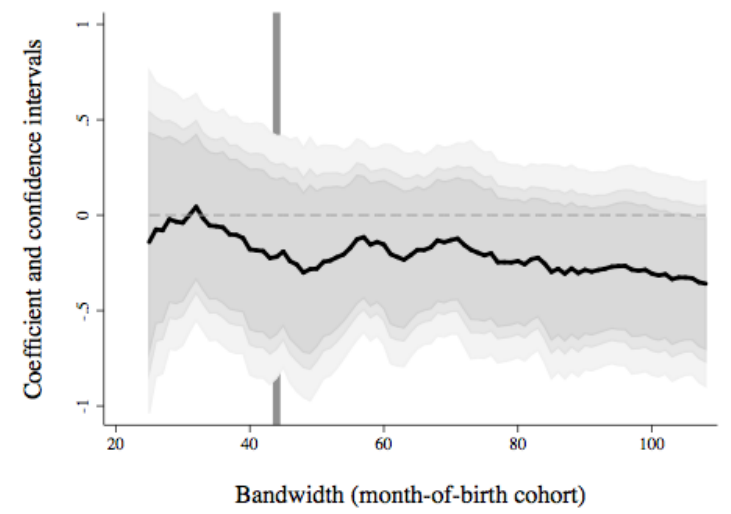

(b) Verbal: Quadratic

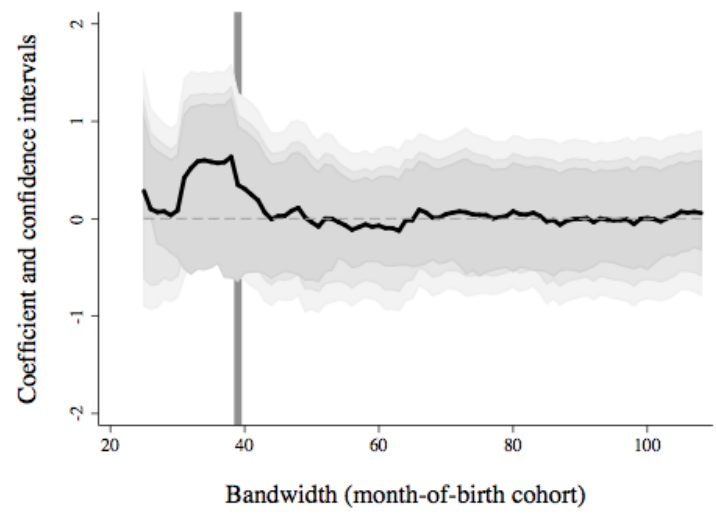

(d) Numeric Ability: Quadratic

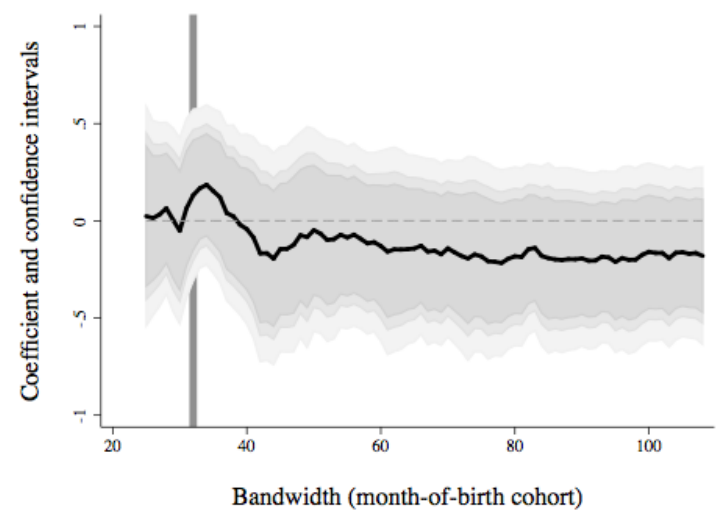


Table 7 reports the main results computed for the full sample: i.e., including respondents who left school at age 17,18 or 19 years, in addition to those who left at 15 or 16 years, and including those who did not report occupation information. Figure 7 reports sensitivity analyses to the bandwidth choice.

Table 7: OLS and RD estimates of the effect of schooling on cognitive outcomes (full sample, i.e., left school $\leq 19$ years)

\begin{tabular}{|c|c|c|c|c|c|c|c|c|}
\hline \multirow[b]{5}{*}{ Years } & \multicolumn{8}{|c|}{ Outcome } \\
\hline & \multicolumn{2}{|c|}{ Word recall } & \multicolumn{2}{|c|}{ Verbal Fluency } & \multicolumn{2}{|c|}{ Numeric Ability } & \multicolumn{2}{|c|}{ Subtraction } \\
\hline & RD1 & $\mathrm{RD} 2$ & RD1 & $\mathrm{RD} 2$ & RD1 & RD2 & RD1 & $\mathrm{RD} 2$ \\
\hline & \multicolumn{8}{|c|}{ (a) RD treatment effect } \\
\hline & 0.32 & 0.41 & 0.24 & 0.29 & 0.01 & 0.10 & 0.03 & 0.02 \\
\hline Std. Err & 0.13 & 0.17 & 0.19 & 0.23 & 0.12 & 0.16 & 0.12 & 0.13 \\
\hline \multirow[t]{2}{*}{$N$} & 2311 & 2311 & 2356 & 2356 & 1645 & 1645 & 2000 & 2000 \\
\hline & \multicolumn{8}{|c|}{ (b) RD treatment effect (Women) } \\
\hline Years & 0.52 & 0.67 & 0.53 & 0.68 & 0.24 & 0.59 & 0.03 & -0.07 \\
\hline Std. Err & 0.26 & 0.31 & 0.34 & 0.43 & 0.22 & 0.71 & 0.26 & 0.26 \\
\hline \multirow[t]{2}{*}{$N$} & 1290 & 1290 & 1316 & 1316 & 916 & 916 & 1115 & 1115 \\
\hline & \multicolumn{8}{|c|}{ (c) RD treatment effect (Men) } \\
\hline Years & 0.22 & 0.23 & 0.06 & 0.06 & 0.24 & -0.09 & 0.00 & 0.07 \\
\hline Std. Err & 0.21 & 0.22 & 0.24 & 0.32 & 0.22 & 0.23 & 0.16 & 0.18 \\
\hline$N$ & 1021 & 1021 & 1040 & 1040 & 729 & 729 & 885 & 885 \\
\hline $\begin{array}{l}p \text {-value of } \\
\text { diff. }\end{array}$ & 0.63 & 0.50 & 0.12 & 0.12 & 0.94 & 0.30 & 0.62 & 0.27 \\
\hline Bandwidth & 30 & 30 & 30 & 30 & 21 & 21 & 26 & 26 \\
\hline
\end{tabular}

Notes: Panel (a) reports results from two FRD regressions assessing the effect of an additional year of schooling on each cognitive outcome. RD1 adjusts for the following covariates: a linear trend in month-year of birth cohort (interacted with the reform dummy), indicators for gender, interview month, interview year and a quadratic term in age. RD2 additionally adjusts for month-of-birth dummies. The standard errors are clustered by month-year of birth cohort. Survey weights adjusting for unit non-response and sample design were used in all specifications. $\operatorname{Panel}(b)$ presents the first-stage statistics. First-stage $\hat{\beta}$ is the coefficient on the reform dummy in the first stage regression. $F$-statistic is the robust F-statistic for the first-stage. Panel (c) shows the sample size. Bandwidth refers to the number of month-year of birth cohorts included in the estimation sample on each side of the treatment cut-off, selected using a data-driven procedure. $N$ is the sample size used in each regression. 
Figure 7: Sensitivity analyses (full sample)

(a) Memory

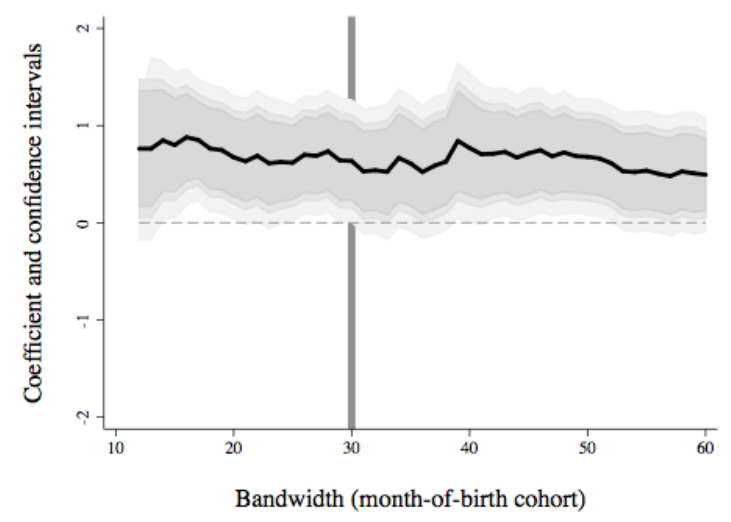

(c) Numeric ability

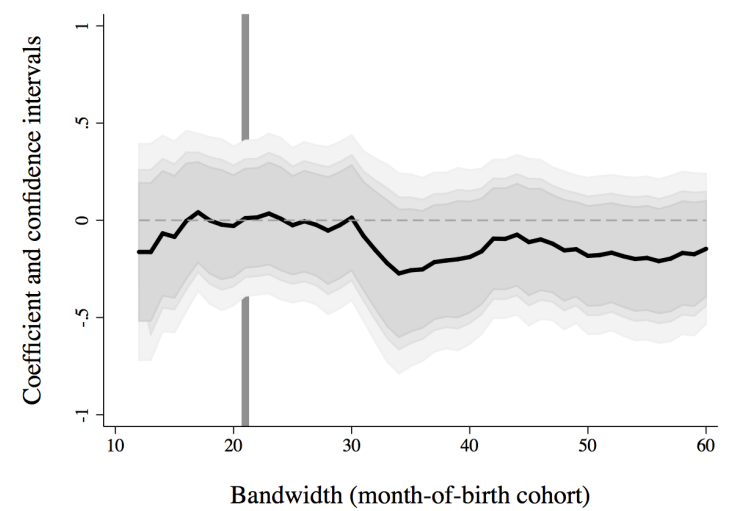

(b) Verbal fluency

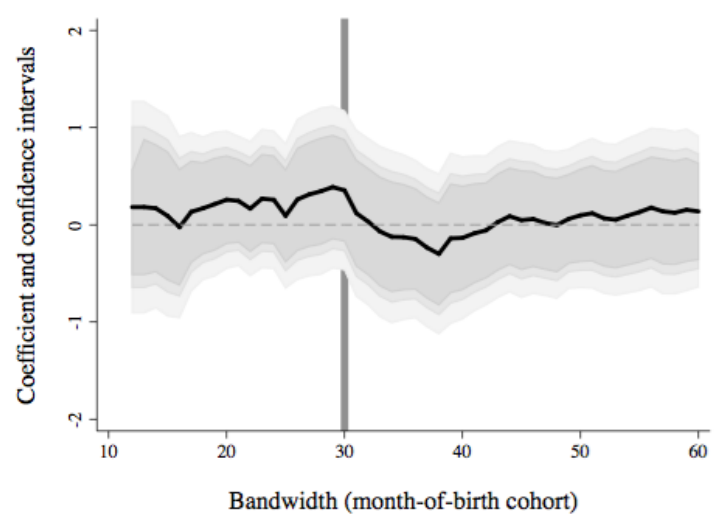

(d) Serial subtraction

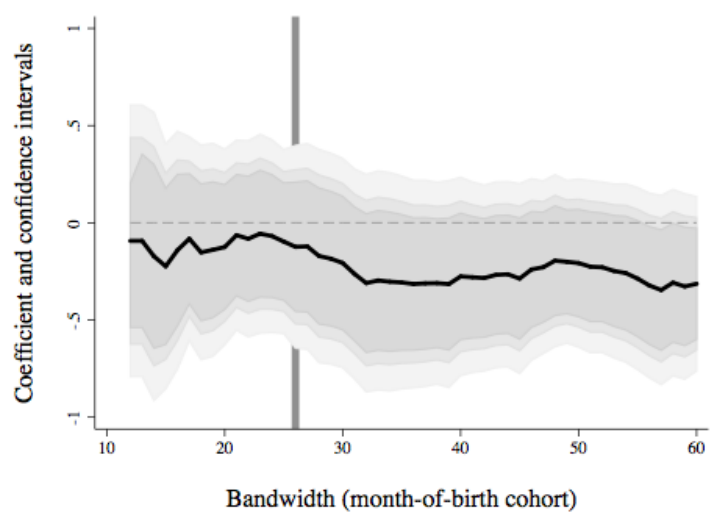

Notes: The bold black line plots coefficients from a fuzzy Regression Discontinuity Design model of the effect of years of school on each cognitive outcome (Word Recall, Verbal Fluency, Numeric Ability, Serial Subtraction) across a range of bandwidth choices (12 month-year of birth cohorts to 60 month-year of birth cohorts). The sample window is determined by bandwidth, measured in month-of-birth cohorts included either side of the 01 September 1957 treatment cut-off. The grey areas depict $90 \%, 95 \%$ and $99 \%$ confidence intervals around the treatment effect. The vertical line indicates the optimally chosen bandwidth. 


\section{Estimation of LACME and LANDE}

The following expressions describe the estimators for the Local Average Complier Mediated Effect (LACME), $\delta(d)$, and the Local Average Natural Direct Effect (LANDE), $\zeta(d)$, developed in Yamamoto (2014). For the categorical mediators (occupation type), the integral was replaced by a summation.

$$
\begin{aligned}
& \tilde{\delta}(d)=\frac{1}{N} \sum_{i=1}^{N} \int \frac{\tilde{Q}_{d \mid d X_{i}} \tilde{G}_{m \mid d d X_{i}} S_{m d d X_{i}}-\tilde{Q}_{d \mid(1-d) X_{i}} \tilde{G}_{m \mid d(1-d) X_{i}} \tilde{S}_{m d(1-d) X_{i}}}{\tilde{Q}_{d \mid d X_{i}} \tilde{G}_{m \mid d d X_{i}}-\tilde{Q}_{d \mid(1-d) X_{i}} \tilde{G}_{m \mid d(1-d) X_{i}}} \\
& \times \frac{\left(\tilde{Q}_{1 \mid 1 X_{i}} \tilde{G}_{m \mid 11 X_{i}}-\tilde{Q}_{1 \mid 0 X_{i}} \tilde{G}_{m \mid 10 X_{i}}-\tilde{Q}_{0 \mid 0 X_{i}} \tilde{G}_{m \mid 00 X_{i}}+\tilde{Q}_{0 \mid 1 X_{i}} \tilde{G}_{m \mid 01 X_{i}}\right)}{\tilde{Q}_{1 \mid 1 X_{i}}-\tilde{Q}_{1 \mid 0 X_{i}}} d m, \\
& \tilde{\zeta}(d)=\frac{1}{N} \sum_{i=1}^{N} \int\left\{\frac{\tilde{Q}_{1 \mid 1 X_{i}} \tilde{G}_{m \mid 11 X_{i}} S_{m 11 X_{i}}-\tilde{Q}_{1 \mid 0 X_{i}} \tilde{G}_{m \mid 10 X_{i}} \tilde{S}_{m 10 X_{i}}}{\tilde{Q}_{1 \mid 1 X_{i}} \tilde{G}_{m \mid 11 X_{i}}-\tilde{G}_{m \mid 10 X_{i}}}-\right. \\
& \left.\frac{\tilde{Q}_{0 \mid 0 X_{i}} \tilde{G}_{m \mid 00 X_{i}} \tilde{S}_{m 00 X_{i}}-\tilde{Q}_{0 \mid 1 X_{i}} \tilde{G}_{m \mid 01 X_{i}} \tilde{S}_{m 01 X_{i}}}{\tilde{Q}_{0 \mid 0 X_{i}} \tilde{G}_{m \mid 00 X_{i}}-\tilde{Q}_{0 \mid 1 X_{i}} \tilde{G}_{m \mid 01 X_{i}}}\right\} \\
& \times \frac{\left(\tilde{Q}_{d \mid d X_{i}} \tilde{G}_{m \mid d d X_{i}}-\tilde{Q}_{d \mid(1-d) X_{i}} \tilde{G}_{m \mid d(1-d) X_{i}}\right.}{\tilde{Q}_{1 \mid 1 X_{i}}-\tilde{Q}_{1 \mid 0 X_{i}}} d m .
\end{aligned}
$$

where, $\tilde{S}_{m d z x}=E\left[Y_{i} \mid M_{i}=m, D_{i}=d, Z_{i}=z, X_{i}=x\right], \quad \tilde{G}_{m \mid t z x}=p\left(M_{i}=\right.$ $\left.m \mid D_{i}=d, Z_{i}=z, X_{i}=x\right), \tilde{Q}_{d \mid z x}=\operatorname{Pr}\left(D_{i}=d \mid Z_{i}=z, X_{i}=x\right)$. 